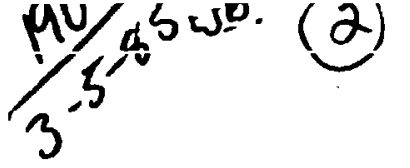

$D x \cdot 0822.2$

ORNL/FEDC-84/6

\title{
COUPLED PLASMA-NeUtral TRANSPORT MODEL FOR THE SCRAPE-OFF REGION
}

\author{
JD. GALAMBOS \\ Y-K.M. PENG \\ D. HEFETZ
}

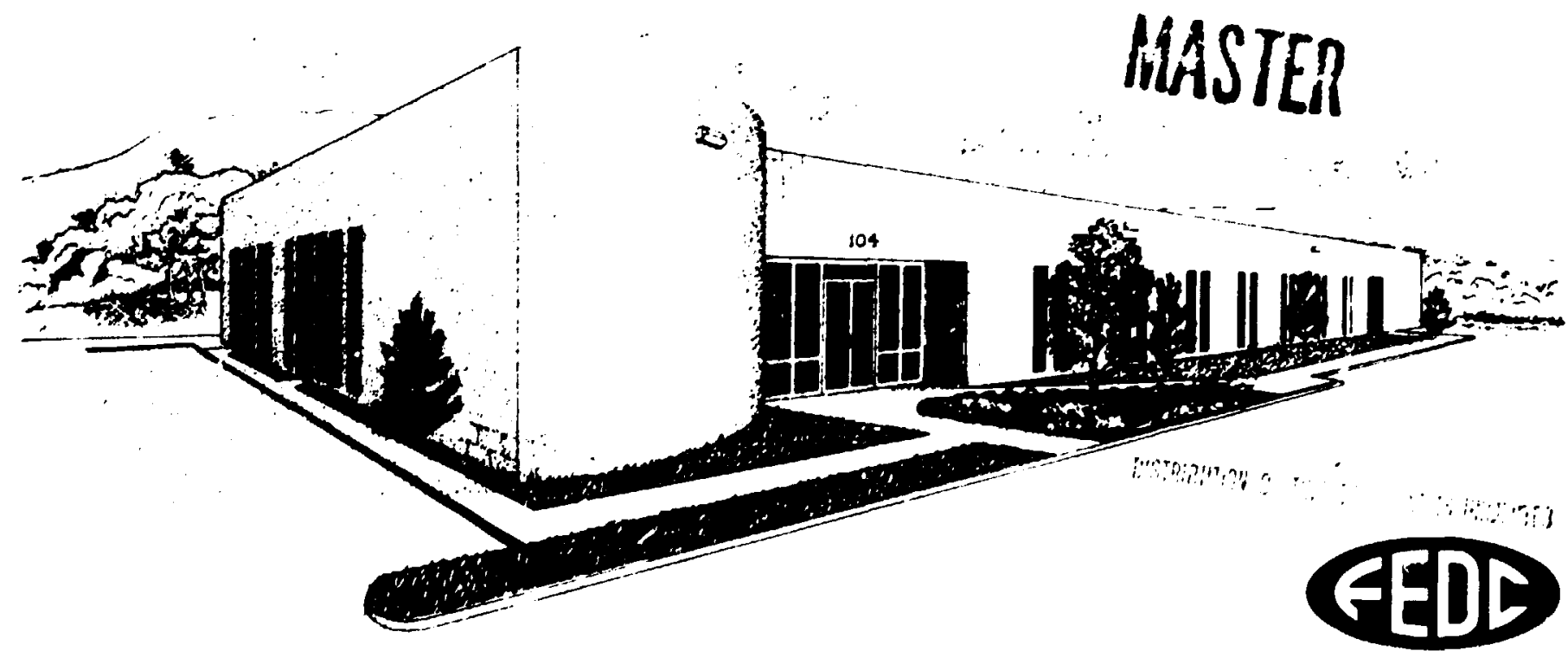

FUSION ENGINEERING DESIGN CENTER

Oak Aidge National Laboratory * Oak Ridge, Tennessee 
ORNL/FEDC-84/6

Dist. Category UC-20 c,d

ORNL/FEDC- $-84 / 6$

Fusion Energy Division

DE85 007559

COUPLED PLASMA-NEUTRAL TRANSPORT MODEL FOR THE SCRAPE-OFF REGION

\author{
J. D. Galambos \\ Y-K. M. Peng \\ D. Heifetz \\ Princet on Plasma Physics Laboratory
}

Date Published - March 1985

Prepared by the

OAK RIDGE NATIONAL LABORATORY

Oak Ridge, Tennessce 37831 operated by

MARTIN MARIETTA ENERGY SYSTEMS, INC.

for the

U.S. DEPARTMENT OF ENERG

under Contract No. DE-AC05-840R21400

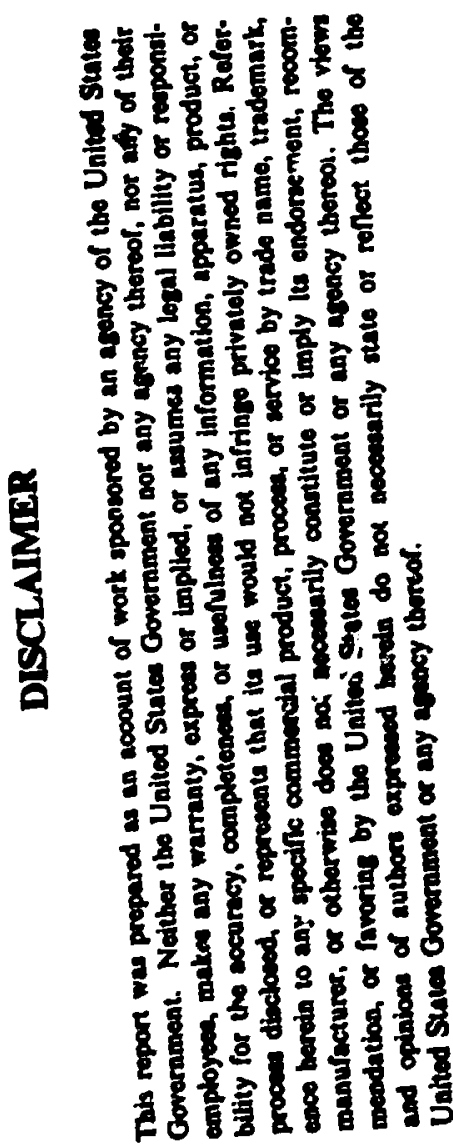


CONTENTS

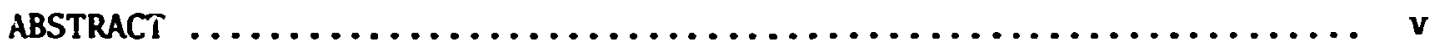

1. INTRODUCTION $\ldots \ldots \ldots \ldots \ldots \ldots \ldots \ldots \ldots \ldots \ldots \ldots \ldots \ldots \ldots \ldots \ldots$

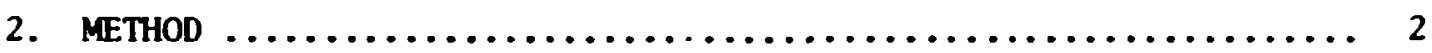

2.1 ITERATION PROCEDURE $\ldots \ldots \ldots \ldots \ldots \ldots \ldots \ldots \ldots \ldots \ldots \ldots \ldots \ldots \ldots \ldots$

2.2 RAdIAL PROFILE MODEL $\ldots \ldots \ldots \ldots \ldots \ldots \ldots \ldots \ldots \ldots \ldots \ldots \ldots$

2.3 TRANSPORT ALONG SCRAPE-OFF FIELD LINES $\ldots \ldots \ldots \ldots \ldots \ldots \ldots 10$

2.4 BENCHMARKING THE NEUTRAL TRANSPORT MODEL $\ldots \ldots \ldots \ldots \ldots \ldots \ldots$

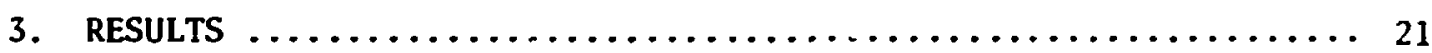

3.1 PUMP-LIMITER C.ASE $\ldots \ldots \ldots \ldots \ldots \ldots \ldots \ldots \ldots \ldots \ldots \ldots \ldots \ldots \ldots \ldots \ldots \ldots$

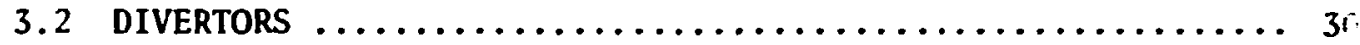

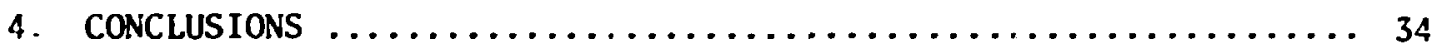

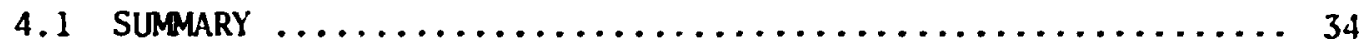

4.2 LIMITATIONS OF MODEL AND FUTURE DIRECTIONS $\ldots \ldots \ldots \ldots \ldots \ldots 34$

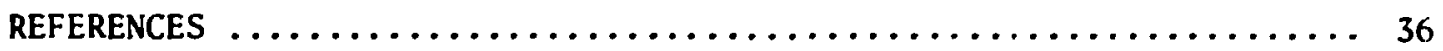




\section{INTRODUCTION}

There are three important considerations in the design of a divertor or pump-limiter for an ignited device: (1) handling the large heat fluxes, (2) coping with the severe material erosion problems, and (3) providing adequate neutral pumping to satisfy impurity exhaust requirements. A growing number of studies on the scrape-off (S.O.) plasma behavior have been undertaken that address these issues. Many of these studies $^{j-5}$ examine the cross-field transport to determine the radial plasma profiles in the S.O. This information is used to detormine the shape of a neutralizing surface that can best handle the heat load. These methods rely on a simplified treatment of the plasme transport along the field lines. More sophisticated mcde $1 s^{6-10}$ have specifically addressed the plasma transport along the S.O. field lines, including the effects of neutral recycling, and have predicted the possibility of strong temperature and density gradients along the field lines. With the occurrence of these gradients, a regime of operation characterized by low temperatures and high densities at the neutralizing plate is identified, which has the beneficial effect of reducing the material erosion rates.

Less attention has been given to the issue of neutral pumping. This problem is becoming more critical with the trend toward smaller ignition devices because of the increasing difficulty of providing large-conductance pumping ducts. The majo:ity of previous predictions of neutral pumping rates $1-3,11,12$ are deri'ed from models that use sizplified treatments of the S.O. plasma transport. However, the more sophisticated models show that when the neutral recycling effects near the neutralizer plate are accounted for, the plasma flow rates into the divertor (pump-iimiter) can be drasticaily reduced (see refs. 6-9 and 13). This study provides a basis for determining neutral pumping rates while retaining the important coupled effects of the plasm. and neutral transport. The method used here involves iteration between models that treat (1) plasma transport acrosis S.0. field lines, (2) plasma transport along S.0. field lines, and (3) neutral transport in the vicinity of the neutralicer plate. The iteration technique and a discussion of the 
individual components involved are presented in the next section, and results for the pump-limiter and divertor cases are described in Sect. 3.

\section{METHOD}

\subsection{ITERATION PROCEDURE}

A flow chart depicting the procedure used to find the pumping rates is shown in Fig. 1. The process begins by calculating the radial plasma profiles in the S.O. The model used for this purpose differs from previously used one-dimensional (1-D) radial transport S.0. models in the treatment of the terms that account for the losses of particles and energy along the field lines. Instead of using the usual assumption of particle flow rate at the sound speed everywhere and the associated convective heat loss for the axial loss terms, a two-point model 13,14 is used here to evaluate these terms. This model is analytic in nature, accounts for the effects of neutral recycling on plasma flow rates along the field, and also includes heat conduction along the field lines. It is necessary to provide the two-point model with a guess for the neutral recycling that occurs at the neutralizer pla:e. Output from this model includes the S.0. width and the radially averaged density and temperatures. These values are used as input to the ZEPHYR $^{8}$ code that mode 15 plasma transport along the field lines. An analytically based neutral transport model that accounts for the pumping effects ${ }^{l}$ is used in conjunction with ZEPHYR. The neutral recycling found in this latter step is zhecked against that assumed in the two-point mode 1, and the entire loop is redone if the recycling values do not coincide. Also, the simple neutral transport model used with ZEPHYR is benchmarked with the Monte Carlo neutral transport code DEGAS. $1 \%$

Each of the components in this iteration loop is inadequate by itself to model the entir ; :ocess of plasma transport in the S.O. Hlong and across the field lines and the coupled effects from neutral transport. Each component relies on input and checks from other components. By separating the modeling process in this manner, it is possible to obtain solutions without excess ve numerical effort while retairing the salient 
OANL-DWG BA-3465 FED

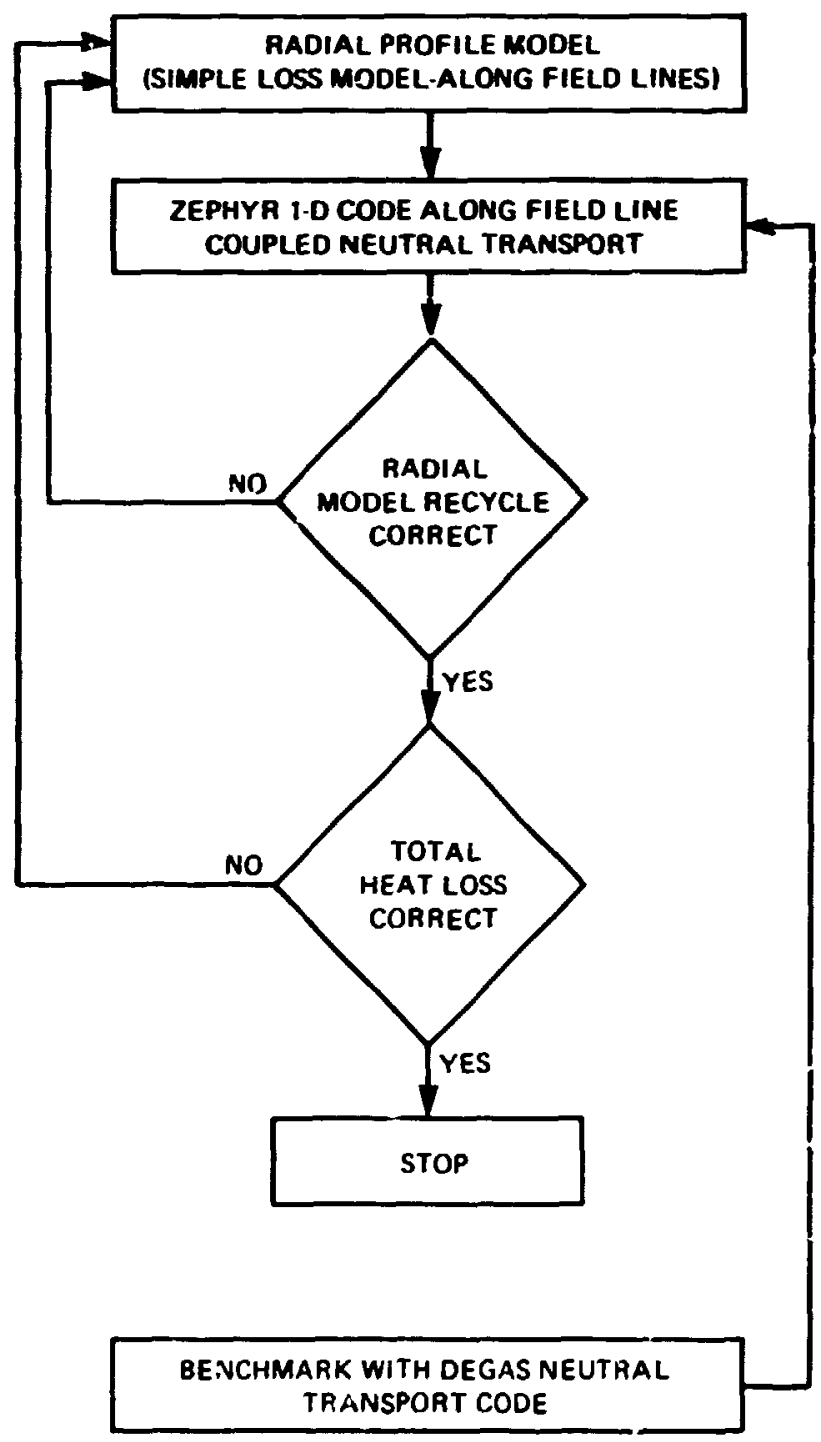

Fig. 1. Flow diagram for the procedure used to model the transport in the scrape-off region. 
features of the individual models. Following is a detailed description of the components.

\subsection{RADIAL PROFI IE MODEL}

The 1-D radial transport equations used for particles and energy are as follows (see ref. 1):

$$
\frac{d}{d r}\left[D \frac{d n(r)}{d r}\right]=S_{n}
$$

and

$$
x \frac{d}{d r}\left\{n(r) d \frac{T(r)}{d r}\right]+3 D \frac{d}{d r}\left[T(r) d \frac{n(r)}{d r}\right]=S_{E},
$$

where $r$ is the direction perpendicular to the field lines, $n$ is density, $T$ is temperature, $D(X)$ is the cross-field particle (energy) transport coefficient, and $S_{n}\left(S_{E}\right)$ is the term. representing particle (energy) loss along. the field lines. Here, it is assumed that $D$ and $\chi$ are constant throughcut the S.O., and the ion and electron temperatures are equal. As shown in $r \in f .1$, if the particle loss term is represented by $n / \tau_{\|}$and the energy loss term by $c n T / \tau_{\|}$, then the solutions for density and temperature are

$$
\begin{aligned}
& n(r)=n_{0} \exp \left(-r / \lambda_{n}\right), \\
& T(r)=T_{0} \exp \left(-r / \lambda_{T}\right),
\end{aligned}
$$

where $c=$ const, $\tau_{\|}=$average ion confinement time (along the field line), and

$$
\lambda_{n}=\sqrt{0 \tau_{\|}},
$$




$$
\lambda_{T}=\frac{2 \lambda_{n} b}{\left[(b+3)^{2}+4 b(c-3)\right]^{1 / 2}-(b+3)},
$$

and

$$
\mathbf{b}=\mathbf{x} / \mathbf{D}
$$

The usual additional assumptions used in the analytic solution are that $\tau_{\|}$is equal to the path length along the S.O. field line L, divided by an average sound speed, and $c=2 \gamma$, where $\gamma$ is an energy transmission coefficient through the shea... at the neutralizer plate. More sophisticated treatments ${ }^{2,3}$ account for the dependence of the sound speed on temperature $(\propto \sqrt{T})$ across the S.O., but these methods must use numerical methods to solve Eqs. (1) and (2).

In situations characterized by high neutral recycling in the vicinity of the neutralizer plate, the particle flow rate along the field lines is often much less than the sound speed (i.e., Mach number « 1) except for a small region adjacent to the neutralizer plate, as seen in ref. 8. This situation is typical for plasma flow into "closed" volumes such as divertors or the bottom (shadow) of a limiter type" envisioned for the Toroidal Fusion Core Experiment (TFCX). ${ }^{16}$ Another consequence of high neutral recycling is the possibility for substantial heat transfer via conduction due to the large temperature gradients that can exist along the field lines. ${ }^{13}$ The methods of refs. 3 and 4 use an additional source term in Eq. (1) to account for the ionization of neutrals formed at the neutralizer plate, but this procedure falls short of including the previously mentioned effects. In order to more properly include the effects of neutral recycling on reducing particle flow rates and introducing heat conduction, the following approach is taken.

At each radial location, the 5.0 . ficld lines are divided into two regions: (1) the length $L_{1}$ alongside the main plasma in which no neutral recycling is accounted for and (2) the length $L_{2}$ in the divertor region (or beneath the 1 imiter) in which all the resycling of neutrals 
formed on the neutralizer plate is assumed to occur. (Calculations presented later indicate that this is a good assumption.) This division of the S.J. region is depicted in Fig. 2. Throughout this work, $L_{l}=$ $4 / 5 \pi R_{p} q$ and $L_{2}=\pi R_{p} q / 5$ are used, where $R_{p}$ is the piasma major radius and $q$ is the safety factor. The common point of the flow regions is designated as the throat $(t)$ entrance. In the first region, it is assumed that the temperature and density are constant along the field line. (Full 1-D calculations along the field 6,8 show that important $n$ and $T$ gradients do appear in region 2.) The values of $n$ and $T$ in region 1 are used as input conditions at the throat for a two-point $\operatorname{method}^{13,14}$ that analyzes the transport along the field between the throat and the neutralizer plate $(p)$. Boundary conditions at the sheath adjacent to the neutralizer plate used in the two-point model are as follows:

$$
\begin{aligned}
& \text { Mach number }=1.0, \\
& \text { heat flux } Q_{p}=2 n \gamma T,
\end{aligned}
$$

and $\gamma=4.0$ is used in all cases here. Also, the neutral recycling coefficient is defined as follows:

$$
R=1-\frac{(n V)_{t}}{(n V)_{p}} \text {, }
$$

where $V$ is the plasma flow speed along the field lines and is specificd for each position $r$. Output from the two-point model includes the heat flux and particle flow speed at the throat. Using these quantities, $\tau_{\|}$ and the coefficient $c$ used in calculating the sink terms from Eqs. (1) and (2) can be expressed as follows:

$$
\tau_{\|}=\frac{L_{1}}{v_{t}}
$$


ORNL-DWG 84-3466 FED

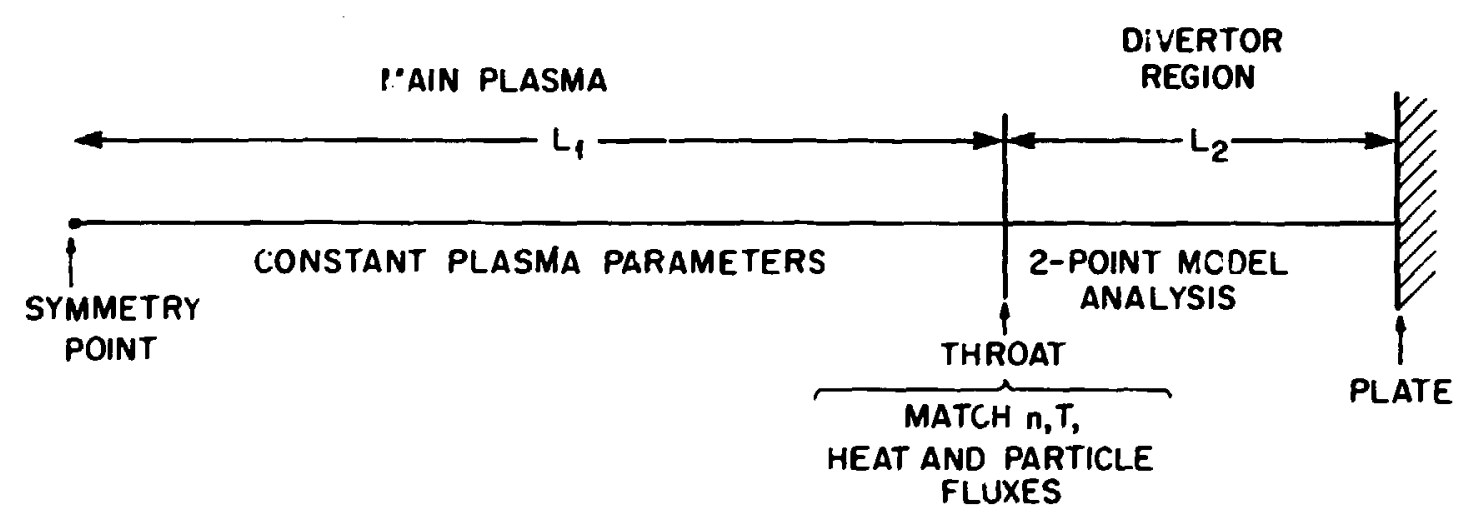

Fig. 2. Division of the length along the field line in the scrapeoff region for modeling purposes. 
and

$$
c=\left(\frac{Q}{n T V}\right)_{t}
$$

The two-point model used here uses $T_{t}$ as input and solves for $Q_{t}$, as opposed to the procedure in Refs. 13 and 14 of inputting $Q_{t}$ and solving for $T_{t}$.

With the framework previously outlined, the radial density and temperature profiles in the S.0. plasma can be solved for with a simple Euler's method as follows. First, the temperature $T(0)$ and density $n(0)$ at the main plasma-S.0. interface $(r=0)$ and a recycling profile $R(r)$ are chosen. Since $\tau_{\|}$and $c$ are approximately constant over some small $\Delta r$, Eq. (3) can be used to estimate the temperature and density at $\mathbf{r}+\Delta \mathbf{r}$. This procedure is carried out over some specified radial extent. Typically, $\Delta \mathrm{r} \leq 2 \mathrm{~mm}$ was sufficient to reach converged solutions for cases in this work.

Tests of this radial profile model for the case $R=0$ and $\tau_{\|}=$const agree with the analytic method of the solution [see Eqs. (3) and (4)]. Another comparison is made with the results of ref. 2 , which assumes $R=0$ but includes the temperature dependence of the flow speed. Figure 3 (taken from ref. 2) shows good agreement between the temperature and density profiles from ref. 2 (solid lines) and the corresponding values calculated with this model (dots for temperature and crosses for density). Both models show a departure from the exponentia! decay shape that is shown for comparison. Also shown in Fig. 3 are results from the radial profile model for the same casc but with a finite $R$. In this case, $R$ is taken to be 0.9 for the first $7.5 \mathrm{~cm}$ away from the main plasma and is decreased linearly to 0.0 over the next $3 \mathrm{~cm}$. In this case, the density decays more slowly than the preceding example in the region of neutral recycling. This rate is slower because of the choking action of the neutral recycling on the flow rate along the field line. For $r<7.5 \mathrm{~cm}$, the flow rate Mach number at the throat is $\sim 0.05$. Despite the reduced particle loss rate along the field lines with recycling included, the 


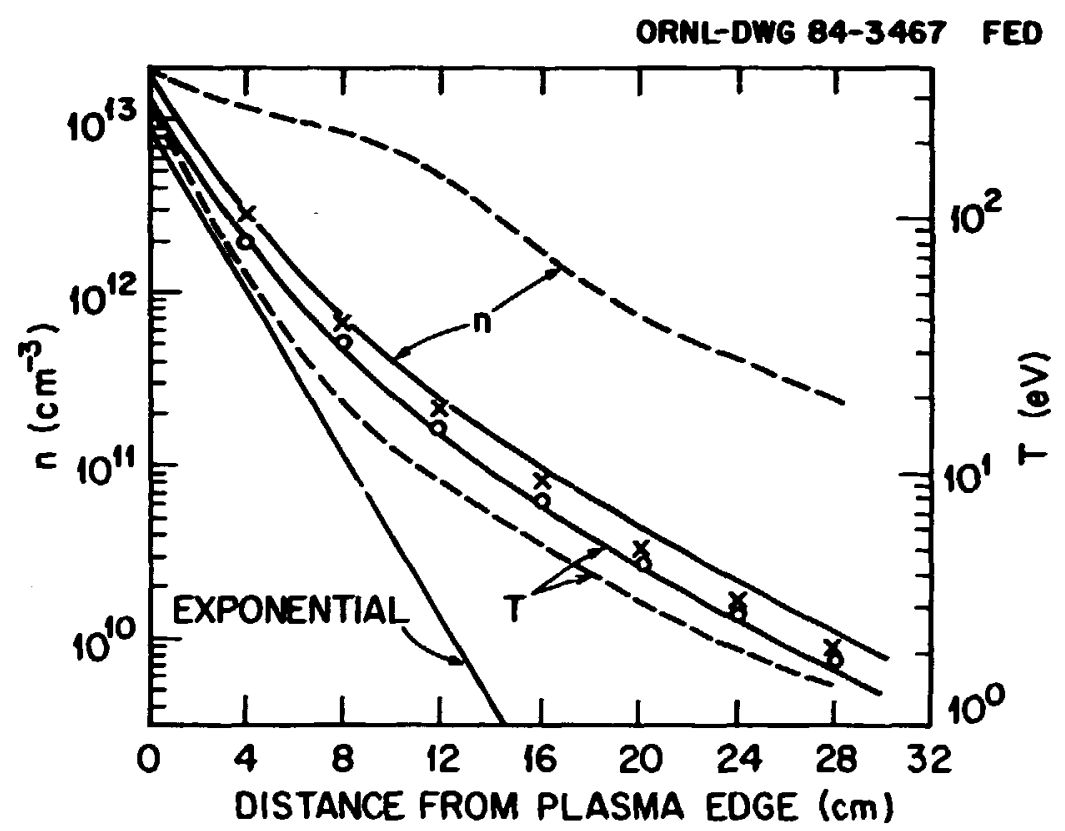

Fig. 3. Comparison of radial temperature and density profiles calculated with models from ref. 2 and the radial profile model presented here. 
temperature falls off even faster than the $R=0$ case. This effect is due to the inclusion of heat conduction losses.

\subsection{TRANSPORT ALONG SCRAPE-OFF FIELD LINES}

The primary tool used to investigate the plasma along S.O. field lines is the ZEPHYR code, ${ }^{8}$ developed at Culham. In order to include the effects of neutral recycling and the evaluation of neutral pumping rates, the neutral transport model described in ref. 11 has been coupled to the version of ZEPHYR used here. Detailed descriptions of ZEPHYR and the neutral transport model are provided in refs. 8 and 11 , respectively, so only brief descriptiors of them are provided here. The primary attention is directed towards the coupling procedure.

The ZEPHYR code finds the steady-state plasma parameters between the watershed (or symmetry) point (point A in Fig. 4) and the neutralizer plate. As depicted in Fig. 4, the present designs envisioned for TFCX incorporate neutral pumping on only one-half of the S.O. plasma (i.e., the inboard sise for the pump-limiter and the outboard side for the divertor). In this study, only the half of the S.O. with pumping is investigated, and symmetry about point $A$ is assumed. ZEPHYR requires input values for the density, the ion and electrc. temperatures at the watershed (taken from the radial profile model), the flow Mach number at the plate $(=1.0$ throughout this work), the ion and electron heat transfer coefficients across the sheath at the plate $(=4.0)$, and the neutral density profile. All cases assume an exponentially decaying neutral density profile:

$$
n_{0}(x)=n_{0} \exp \left(-x / \lambda_{0}\right)
$$

where $X$ is the distance along the field line from the neutralizer plate and $\lambda_{0}$ is an average noutral mean free path (MFP), which is approximated as: 
ORNL-DWG 84-3468 FEO
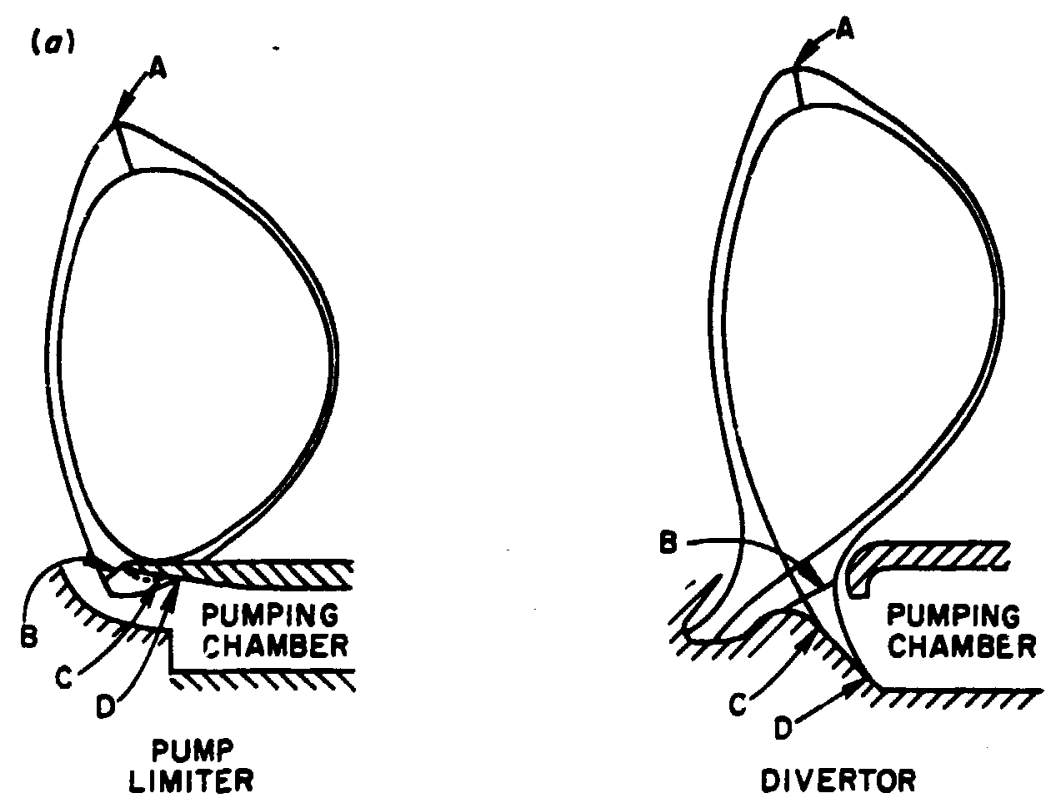

(b)

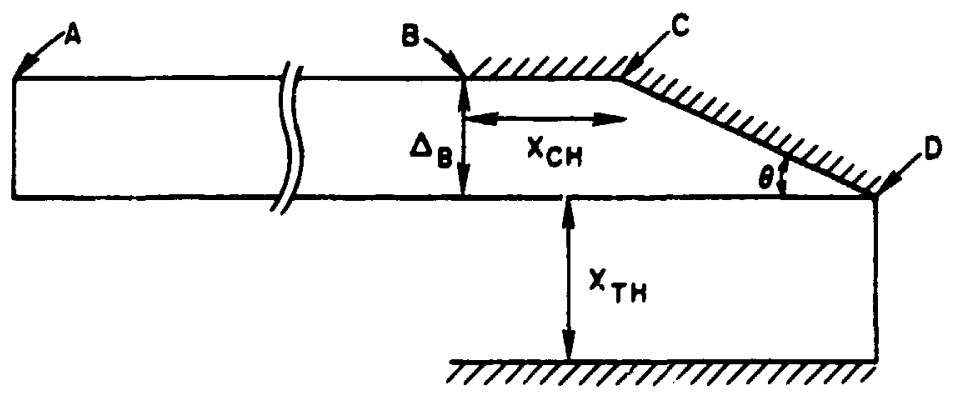

Fig. 4. (a) Schematic of actual scrape-off geometry. (b) Approximate geometry used in ZEPHYR and the simple neutral transport mcdel (SNTM). 


$$
\lambda_{0}=B_{T} / B_{p}\left[R_{n}\left(\frac{1}{\lambda_{i}}+\frac{1}{\lambda_{c x}}\right)^{-1}\right]_{f}+\left(1-R_{n}\right)\left(\lambda_{c x}\right)_{s},
$$

where $B_{T}\left(B_{p}\right)$ is the toroidal (poloidal) magnet: field, $R_{n}$ is the percent of neutrals reflected as fast (f) neutrals off the neutralizer plate (see ref. 11), $\left(1-R_{n}\right.$ ) is the percentage reflected as slow (s) neutrals, and $\lambda_{i}\left(\lambda_{c x}\right)$ is the ionization (charge-exchange) MFP. The ionization rete of neutrals in the divertor channel is simply

$$
\left.\Gamma_{i}=\int_{p}^{t} n \times n_{0}<\sigma v\right\rangle_{\text {ionization }} d x
$$

The coefficient $n_{0}$ in Eq. (9) is determined through the iteration procedure described in the following paragraphs.

The netural transport model from ref. 11 is analytic ir nature, which allows for a fast iteration procedure with the ZEPHYR code. Calculations are based on neutral MFPs evaluated with average plasma density and temperatures. Output from this model ilcludes the fraction of the neutral flux produced at the neutralizer plate that either is pumped $\left(f_{p}\right)$ or escapes the divertor channel back toward the main plasma $\left(f_{E}\right)$.

The geometry used in the zutraj transport model is shown in Fig. 4. Only the region in the vicinity of the neutralizer plate (between points $B$ and $D$ in Fig. 4) is included in this model since the neutral density falls off rapidly with distance from the neutralizing surface. ${ }^{17}$ The scrape-off plasma enters the divertor channel with a width $\Delta$ and is incident on the neutralizer plate after a distance $x_{c}$ along the channel. The neutralizing surface is oriented at an angle $\theta$ to the plasma flow, which produces a wedge-shaped plasma poloidal cross section adjacent to the neutralizer platic. A void region of thickness $x_{T H}$ exists between the scrape-off and the chamber wall. The neutral transport model in ref. 11 involves finding the average probability that a neutral produced on the plase can escape through the wedge-shaped profile. Tile net neutral flux leaving the scrape-off is decermined, accounting for 
multiple reflections off the chamber walls and passes through the scrape-off plasma [see Eqs. (35)-(44) in ref. 11]. The portion of this neutral flux that is pumped, $f_{p}$, is governed throug? a balance of the effective area of the pumps, $A_{\text {pump' }}^{*}$ and the surface area of the plases in the divertor channel, $A_{p}$. Equation (42) from ref. 11 (which depends on the pump speed $S$, duct conductance $C$, and number of purps $N$ ) is used for $A_{\text {pump }}^{\star}$ :

$$
\begin{aligned}
& A_{\text {pump }}^{*}=4 / C_{0} \times S_{\text {eff }}, \\
& A_{p}=2 \pi R_{p}\left(X_{c}+\Delta / \sin \theta\right),
\end{aligned}
$$

where $S_{\text {eff }}$ is the effective pump speed $\left[\mathrm{N}\left(\mathrm{S}^{-1}+\mathrm{C}^{-1}\right)^{-1}\right], \mathrm{C}_{0}$ is the average wall temperature $(300 \mathrm{~K})$ molecular speed, and $R_{p}$ is the major plasma radius $(=3.5 \mathrm{~m})$.

The fraction of the neutral flux exiting the scrape-off that escapes toward the main plasma, $f_{E}$, is

$$
f_{E}=\frac{A_{E}}{A_{p}} \exp \left(-x_{c} / \Delta_{z}\right),
$$

where $A_{E}$ is the escape area $=2 \pi R\left(X_{T H}+\Delta\right)$ and $\Delta_{Z}$ is the attenuation factor given by $\mathrm{Eq} .(51)$ in ref. 11 .

In the following results, the pumped and escaping fractions of neutrals ( $f_{p}$ and $f_{E}$ ) are multiplied by the correcting factors $C_{p}$ and $C_{E}$, respectively. These factors are determined through checks with the Monte Carlo neutral transport code DEGAS ${ }^{15}$ as described in the following paragraphs. Also, when used in conjunction with ZEPHYR, the average density and temperatures between the throat (point B) and neutralizer plate are used to evaluate MFPs.

The iteration procedure between ZEPHYR and the neutral transport model involves changing the coefficient $n_{0}$ in $E q$. (9) to satisfy the steady-state neutral particle balance: 


\section{$1:$}

ionization rate + puming rate + escape rate $=$ production rate.

Provided with an initial guess for the neutral density profile in the plasma [see Eq. (9)], ZEPHYR calculates the plasma conditions at the neutralizer plate. With the additional knowledge of the scrape-off width (from the radial profile model), the total neutral production rate, $\left(2 \pi R_{p}{ }_{p} / B_{T}\right) \Delta(n v)_{p}$, can be determined, and the fractions that are pumped and that escape are provided by the neutral transport model. Also, the neutral ionization rate is provided by Eq. (11). The neutral density coefficient $n_{0}$ is adjusted so that the total sink rate of neutral particles [left-hand side of Eq. (15)] balances the production rate. This iteration process is compiicsted by the fact that modifications of the neutral density shange the plasma conditions at the plate and hence change the neutral production rate.

\subsection{BENCHMARKING THE NEUTRAL TRANSPORT MODEL}

Before applications of the iteration procedure between the plasma transport and the neutral transport are presented, a tenchmarking of the neutral trensport model previously discussed, henceforth referred to as the simple neutral transport model (SNTM), with the DEGAS code is discussed. The DEGAS code can account for the detailed geometry of the limiter (divertor) configuration and the effects of plasma variation to a much greater extent than the SNTM. Some reference comparison cases between the two models are discussed in the following paragraphs.

The geometry used in the DEGAS modeling of the limiter region is shown in Fig. 5. Solid lines represent material walls, and dotted lines represent computational boundaries. The upper zones contain plasma, and the bottom zone is void. A uniform source of plasma is initiated along the neutralizer plate, and pumping is simulated by modeling some wall zones as pump ducts and specifying that is fraction of the neutrals hitting these zones is absorbed. The absorbed fraction is 


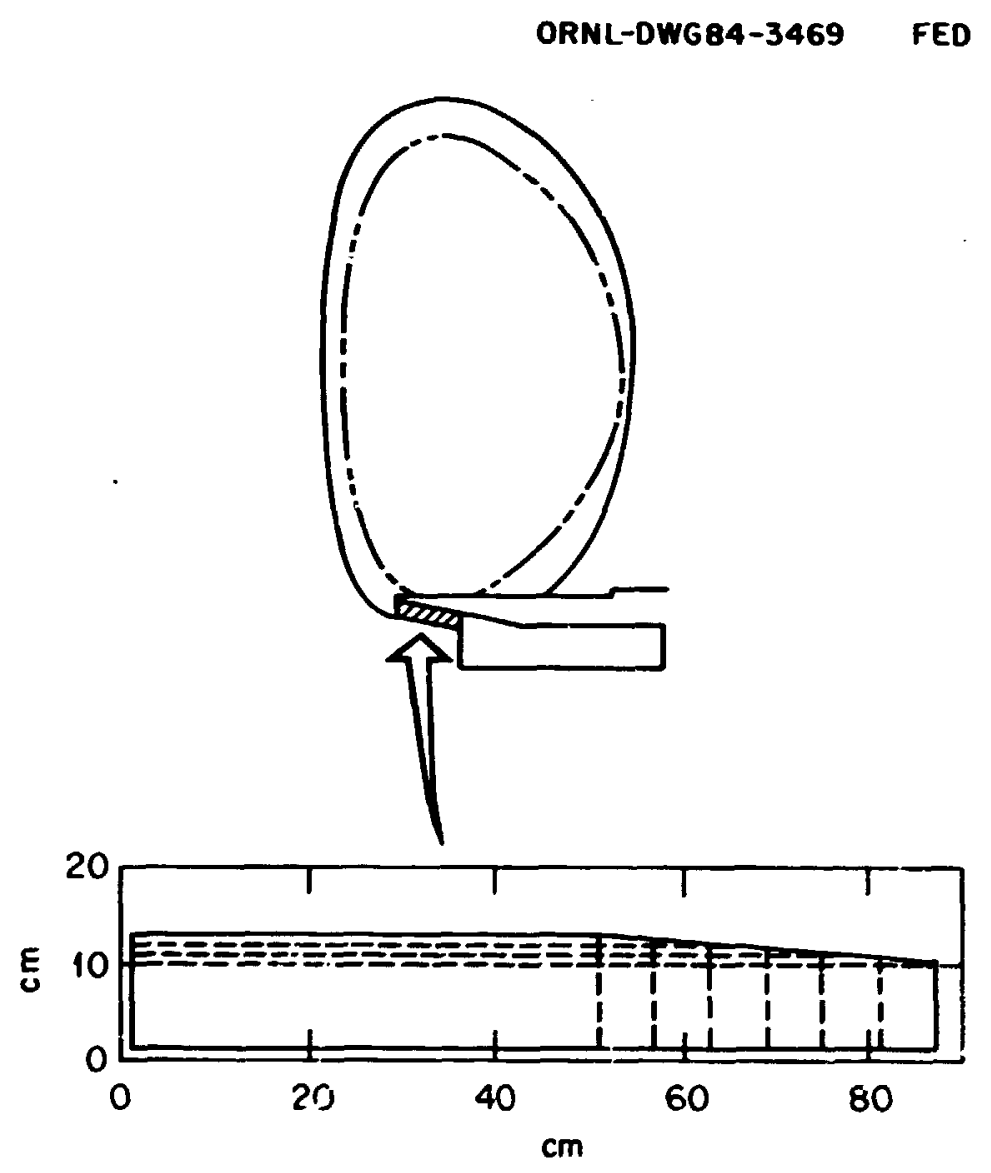

Fig. 5. Genmetry used in DEGAS fnr modeling of neutral transport below limiter. 


$$
f_{\text {abs }}=\frac{A_{\text {pump }}^{\star}}{2 \pi R_{p} \times l_{\text {abs }}} \text {, }
$$

where $l_{\text {abs }}$ is the length of the wall segments modeled as pump ducts. Neutrals that leave through the opening at the left-hand side of the configuration in Fig. 5 are escaping neutrals. The corresponding parameters used in the simple neutral transport model are $X_{c}=50 \mathrm{~cm}$, $\lambda_{\text {TH }}=9 \mathrm{~cm}, \Delta=3 \mathrm{~cm}$, and $\theta=5^{\circ}$. For the limiter case, a uniform plasma density and temperature are used in the DEGAS calculations. Table 1 compares the pumping and escaping fractions as calculated for some typical plasma conditions below the limiter. Results from DEGAS are averaged over runs done with pumping ai various wall segments. The results from SNTM are found using the factors $C_{F}=0.8$ and $C_{E}=1.5$ for the pumping and escaping fractions. With the values, the pumping fractions found with SNTM are within $\sim 10 \%$ of these predicted by DEGAS, and the escaping fractions are within $\sim 20 \%$ of the DECAS results. The preceding values for $C_{p}$ and $C_{E}$ are used for all the limiter cases throughout this work.

The method of modeling the neutral transport for the divertor case is slightly different from that for the limiter cases. For TFCX, the flux surfaces in the divertor shamber are expanded by about a factor of 3 compared to the spacing at the midplane. To account for this, the S.0. thickness provided by the radial profile code is increased by three in the SNTM, and to conserve the total number of particles the density used in the neutral transport calculations is taken to be one-third of that predicted, assuming a constant cross-sectional area S.0. Also, for the divertor cases, the S.O. thickness used in the SNTM is increased an additional $30 \%$ to account for the spreading of the plasma across the main plasma side of the separatrix in the divertor chamber, where it is unopposed by a confined plasma.

The geometry used in DEGAS for the divertor option is shown in Fig. 6. With the preceding considerations in mind, the corresponding inputs used in the SNTM are $X_{c}=50 \mathrm{~cm}, X_{T H}=20 \mathrm{~cm}, \Delta=5 \mathrm{~cm}$, and 
Table 1. Comparison of pumped and escaping fractions of the neutral flux produced at the plate for the limiter option, as predicted by DEGAS and the SNTM

\begin{tabular}{|c|c|c|c|c|c|}
\hline \multicolumn{2}{|c|}{ Case } & \multicolumn{2}{|c|}{ Pumped fraction ( $(\delta)$} & \multicolumn{2}{|c|}{ Escaping fraction ( 8} \\
\hline Plasma conditions & Pump speed & DEGAS & SNTM & DEGAS & SNTM \\
\hline \multicolumn{6}{|l|}{$\mathrm{n}=8.2 \times 10^{12} \mathrm{~cm}^{-3}$} \\
\hline$T_{e}=18 \mathrm{eV}$ & $1.6 \times 10^{5} \mathrm{~L} / \mathrm{s}$ & 8.6 & 9.6 & 6.9 & 8.7 \\
\hline $\begin{array}{l}\mathrm{T}_{\mathrm{i}}=13 \mathrm{eV} \\
\mathrm{n}=5 \times 10^{12} \mathrm{~cm}^{-3}\end{array}$ & $2.2 \times 10^{5} \mathrm{~L} / \mathrm{s}$ & 12.8 & 12.6 & 7.3 & 7.8 \\
\hline $\mathrm{T}_{\mathrm{e}}=30 \mathrm{eV}$ & $1.6 \times 10^{5} \mathrm{~L} / \mathrm{s}$ & 8.3 & 8.9 & 8.8 & 7.4 \\
\hline $\mathrm{T}_{\mathrm{i}}=20 \mathrm{eV}$ & $2.2 \times 10^{5} \mathrm{~L} / \mathrm{s}$ & 11.6 & 11.6 & 8.2 & 7.14 \\
\hline
\end{tabular}

Using 16 ducts with $C=19 \mathrm{~m}^{3} / \mathrm{s}$ and $\mathrm{S}=50 \mathrm{~m}^{3} / \mathrm{s}$.

$b_{\text {Using }} 16$ ducts with $C=15 \mathrm{~m}^{3} / \mathrm{s}$ and $S=30 \mathrm{~m}^{3} / \mathrm{s}$. 

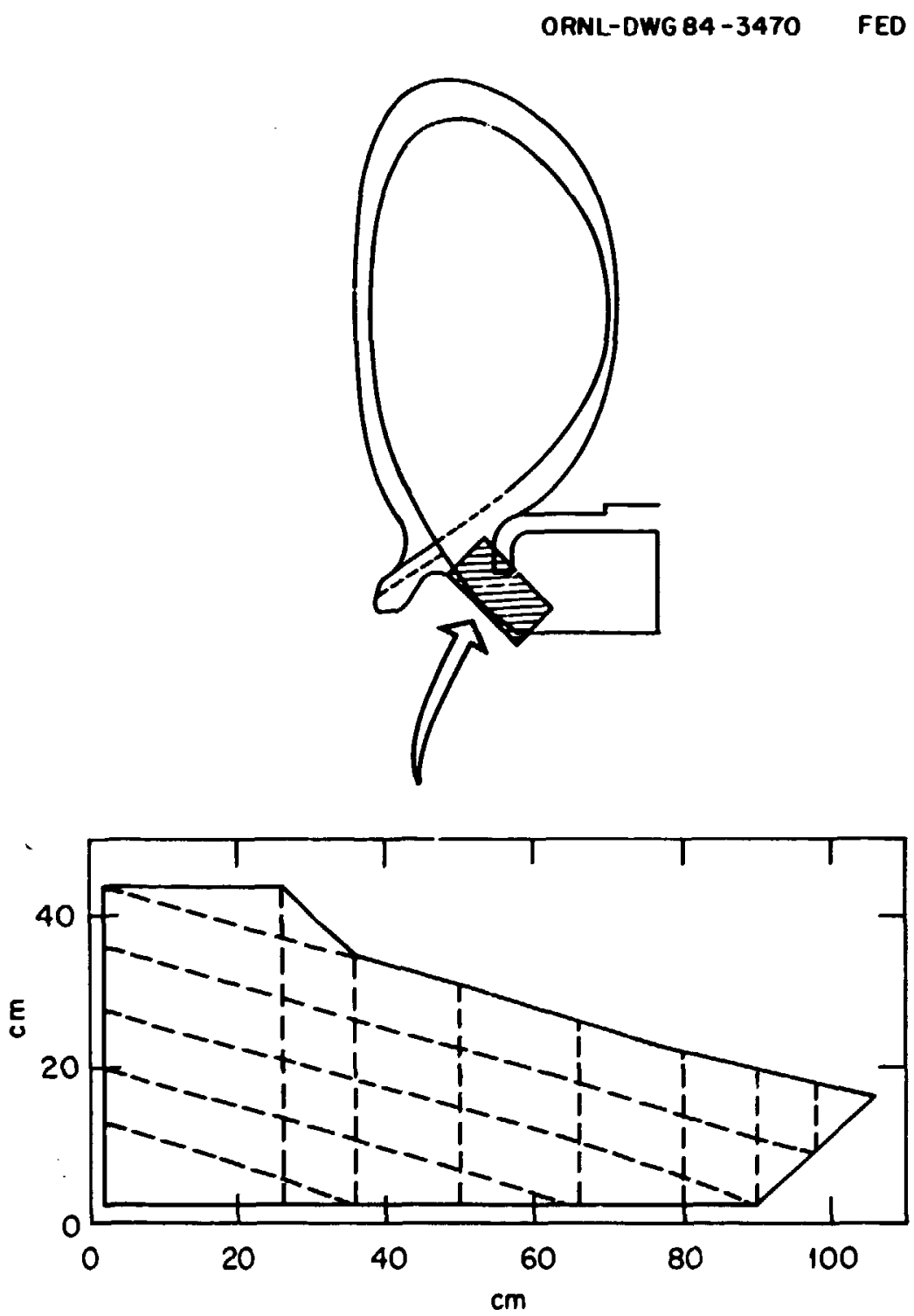

Fig. 6. Geometry used in DEGAS for modeling of neutral transport in divertor. 
$\theta=15^{\circ}$. For the divertor case, the plasma parameters vary greatly in the radial direction in the area of interest for pumping calculations. In the limiter case, only the outer portion of the S.O. that is incident on the bottom of the limiter is of concern for neutral pumping calculations. To take some account of the large variations in plasma parameters for the divertor case, simple profiles for temperature and density are included in the DEGAS calculations. Higher densities and temperatures ("peak" values) are used in the zone above the separatrix (see Fig. 6) compared with the plasma in the zones above and below it ("low" values). The average value of the profiles is used in the SNTM for these comparisons. Table 2 shows the pumping and escaping fractions of the neutrals as calculated with the twi neutral transport models for several cases. For these runs, the coefficien's $C_{p}=0.47$ and $C_{E}=0.48$ are used in the SNTM, and good agreement between the results of the two models is observed. These values for $C_{E}$ and $C_{p}$ are also used for the zest of the divertor cases discussed in this work.

Even though the SNTM cannot be expected to provide detailed information on the neutral transport, the preceding coinparisons indicate that it can be used to provide estimates on overall quantities, such as the fraction of reutrals being pumped or the fraction escaping the divertor chamber. However, the simple model does need to be checked for each geometry, as indicated in the different correction factors $\left(C_{E}\right.$ and $\left.C_{P}\right)$ found for the preceding limiter and divertor examples. We note that even with $C_{E}=C_{p}=1.0$, the simple model results show good agreement with those from DEGAS for the fraction of neutrals that are ionized (i.e., $1-f_{p}-f_{E}$ ), which is about $80 \%$ for the preceding cases. It is the lower fractions of pumping and escaping neutrals, which are of particular interest, that require calibration with sophisticated models. The importance of coupling the neutral and plasma transport is also evident in the preceding comparisons with the observation that large percentagts of the neutrals produced on the plate are ultimately ionized in the S.0. (i.e., high neutral recycling). A final comment on the neutral transport modeling is that only hydrogen neutrals are considered. Throughout this work, transport of helium is assumed to be equivalent to that of hydrogen. 
Table 2. Comparison of pumping and escaping fractions of the neutral flux produced at the plate for the divertor option as predicted by DEGAS and the SNTM

\begin{tabular}{|c|c|c|c|c|c|c|}
\hline \multicolumn{2}{|l|}{ Case } & \multicolumn{2}{|c|}{ Pumping fraction ( $(q)$} & \multicolumn{2}{|c|}{ Escaping fraction ( $(\xi)$} & \\
\hline Plasma conditions & Pump speed & DEGAS & SNTM & DLGAS & SNTM & \\
\hline $\mathrm{n}=\begin{array}{l}3 \times 10^{12} \mathrm{~cm}^{-3} \text { peak } \\
7 \times 10^{12} \mathrm{~cm}^{-3} \text { low }\end{array}$ & $1.1 \times 10^{5} \mathrm{~L} / \mathrm{s}^{a}$ & 1.7 & 1.6 & 16 & 1.6 & \\
\hline $\mathrm{T}=\begin{array}{l}120 \mathrm{eV} \text { peak } \\
30 \mathrm{eV} \text { low }\end{array}$ & $2.1 \times 10^{5} \mathrm{~L} / \mathrm{s}^{b}$ & 3.1 & 3.2 & 16 & 16 & $\tilde{O}$ \\
\hline $\mathrm{n}=\begin{array}{l}5 \times 10^{12} \mathrm{~cm}^{-3} \text { peak } \\
2 \times 10^{12} \mathrm{~cm}^{-3} \text { low }\end{array}$ & $1.1 \times 10^{5} \mathrm{~L} / \mathrm{s}$ & 1.7 & 1.7 & 19 & 18 & \\
\hline $\mathrm{T}=\begin{array}{l}150 \mathrm{eV} \text { peak } \\
30 \mathrm{eV} \mathrm{low}\end{array}$ & $2.1 \times 10^{5} \mathrm{~L} / \mathrm{s}$ & 3.0 & 3.4 & 18 & 17 & \\
\hline \multicolumn{7}{|c|}{$\begin{array}{l}a_{N}=16, C=10 \mathrm{~m}^{3} / \mathrm{s}, S=20 \mathrm{~m}^{3} / \mathrm{s} \\
b_{N}=16, C=20 \mathrm{~m}^{3} / \mathrm{s}, S=10 \mathrm{~m}^{3} / \mathrm{s}\end{array}$} \\
\hline
\end{tabular}




\section{RESULTS}

The modeling technique described in Sect. 2 is applied here to study the neutral pumping rates for pump-limiter ard divertor configurations. In order to illustrate the modeling techrique, the iteration process used for the first example in Sect. 3.1 is described in detail. Subsequently, the results and the trends they exhibit are emphasized. The results in this section also address the sensitivity of the calculated pumping rates to changes in various assumptions and boundary conditions.

\subsection{PUMP-LIMITER CASE}

The first step in the S.0. modeling technique involves using the radial profile model to find the average density and temperature in region 1 of the S.O. (see Fig. 2) and the S.0. thickness. Figure 7 shows tise temperature and density in region 1 vs distance from the main plasma. This case is for a density of $5 \times 10^{13} \mathrm{~cm}^{-3}$ and a temperature of $140 \mathrm{eV}$ at the main plasma scrape-off interface (edge) and uses $D=x=10^{4} \mathrm{~cm}^{2} / \mathrm{s}$ for the particle and energy transport coefficients. Also shown is the assumed neutral recycling profile, $R$, which is determined in the following manner.

For the limiter case, recycling in the S.0. plasma is divided into two radial categories: (1) the S.0. portion incident on the top of the limiter and (2) the outer part of the S.O. that is incident on the bottom face of the limiter. Recycling in the first region is assumed to be small since the neutrals are not restrained by any material surface from entering the closed-field region. Recycling in the latter category is high since the geometry is "closed" and the neutrals are unlikely to penetrate back toward the main plasma. Sensitivity to changes in the low recycling assumption in the first region is addressed later. The location of the limiter's leading edge, which is the demarcation for the portion of the S.O. that flows below the limiter, is determined by the criterion that the heat flux has fallen to $200 \mathrm{~W} / \mathrm{cm}^{2}$. For this example, the leading edge is $2.2 \mathrm{~cm}$ into the scrape-off. The recycling coefficient 


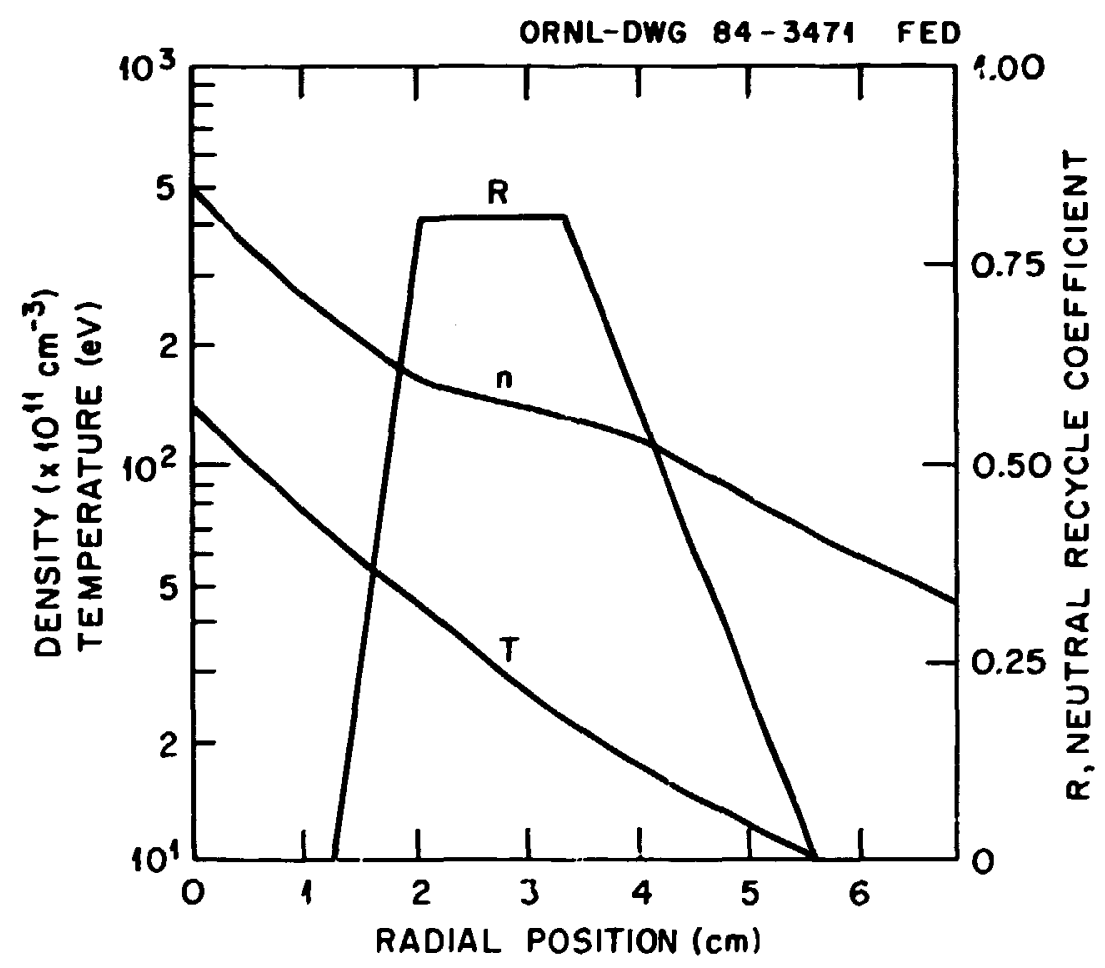

Fig. 7. Density $n$, temperature $T$, and neutral recycle coefficient $R$ vs radial distance from main plasma for a limiter case. 
is increased to the prescribed value underneath the limiter, beginning $1 \mathrm{~cm}$ from the leading edge. Also, the recycling coefficient is ramed down to zero after the plasma temperature (average of the throat and plate values) falls below $20 \mathrm{eV}$ since the neutral ionization probability begins to rapidly drop below this temperature. 18 The range over which the recycling is decreased to zero is taken to be between the points where the temperature lies between $20 \mathrm{eV}$ and $10 \mathrm{eV}$. Proper treatment of the cold $(<10-e V)$ outer edge of the scrape-off requires a more detailed neutral transport model than the method used here, which relies on average densities and temperatures. The sensitivity of the results to variation in the recycle cutoff in the cold outer extent of the S.0. is addressed later. Finally, we note that in practice the actual determination of where to ramp the recycling coefficient up and down to satisfy the preceding sriteria requires several iterations.

The distinguishing feature in Fig. 7 is the reduced rate of density falloff in the region of high neutral recycling, similar to the trend noticed in Fig. 3. Also, it is evident that the temperature falloff is not reduced in this region because heat conduction allows energy transport $a^{1}$ ong the field lines even though the particle flow rate in that direction is reduced. The integrated heat flux (Q) onto the limiter is $48 \mathrm{MW}$ (including the outboard half of the scrape-off that is assumed to be the same as the inboard half modeled here). To arrive at a different integrated value for total heat flux, the starting values for $n$ and/or $T$ at the edge of the main plasma must be changed accordingly and the preceding process repea' $\mathrm{d}$.

the information displayed in Fig. 7 includes the thickness of the scrape-off plasma that flows behind the limiter $\Delta$ and the average throat density $\vec{n}$ and temperature $\bar{T}$ of the plasma :hat flows behind the limiter. The thickness $\Delta$ is taken to be the radial distance from the leading edge to the point where the neutral recycling is assumed to go to zero. This information is used as input for the coupled ZEPHYR-neutral transport model calculation. Results for the plasma profiles along the field lines calculated with this model are shewn in Fig. 8. The plasma density $n$, temperature $T$, and f.ow speed $V$ are relatively constant in 


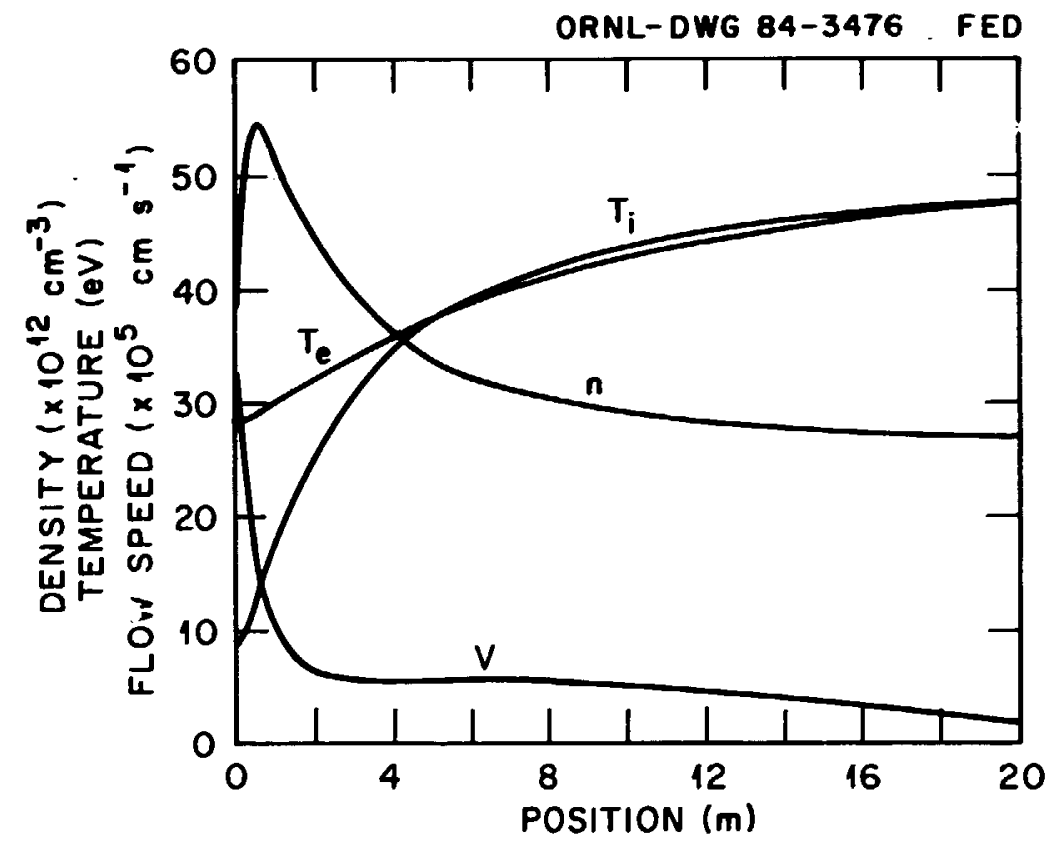

Fig. 8. Ion temperature $T_{i}$, electron temperature $T_{e}$, density $n$, and flow speed $V$ vs distance along the field line from the neutralizer plate for a limiter case. 
the region adjacent to the main plasma [4 $\mathrm{m}<\ell<20 \mathrm{~m}$ ] with the gradients occurring pretominantly in the "divertor" region [0 $\mathrm{m}<\ell<4 \mathrm{~m}$ ]. The localization of the gradients near the neutralizer plate supports the approximation made in Sect. 2.1 with regard to the use of constant plasma parameters along the field lines in region 1 . The neutral ransport calculations done in the ZEPHYR loop use the average of the plate and throat values for density and temperature and use the pumplimiter geometry described in Sect. 2.3. For this example, a punping system of 16 pumps with speeds $=5 \times 10^{4} \mathrm{~L} / \mathrm{s}$ and ducts with conductance $=1.9 \times 10^{4} \mathrm{~L} / \mathrm{s}$ corresponding to $\mathrm{S}_{\text {eff }}=2.2 \times 10^{5} \mathrm{~L} / \mathrm{s}$ is modeled. The net plasma current entering the limiter shadow region for this case is $7.4 \times 10^{21} \mathrm{~s}^{-1}$, of which $4.7 \times 10^{21} \mathrm{~s}^{-1}(63 \%)$ are pumped as neutrals. Also, the neutral recycling in the divertor channel [Eq. (6)] for these plasma conditions is 0.8 , which is consistent with the assumed recycling in the preceding radial profile calculation. In practice, several iterations between the radial profile model and the ZEPHYR-neutral model are needed to reach a consistent neutral recycling value.

Table 3 shows results for several other cases found using the procedure previously described. These cases investigate the effects on the calculated neutral pumping rates caused by variations in the assumed conditions at the main plasma-S.0. interface and by changes in the assumptions used in the model. Values provided by the radial profile model $\left(Q, \bar{n}, \bar{T}, \Delta_{S .0 .}, \Delta, f_{B L}\right)$ are indicated in the left-hand columns. Here $\Delta_{S .0}$, is the total S.0. width, including the portion incident on the front surface of the limiter, and $f_{B L}$ is the fraction of the plasma flow out of the S.0. region (along the field line) that flows below the limiter. Output from the coupled ZEPHYR-neutral model for the recycling value $R$, the neutral pumping rate $\Gamma_{p}$, and the fraction of the plasma flow into the throat that is pumped $f$ are shown in the right-hand columns. All cases in Table 3 use the same pump speed as the case just described (case 1).

In comparing the neutral pumping rates in Table 3 , the following scalings should be kept in mind. The neutral pumping rate is proportional to the total particle flow underneath the limiter (into the 
Table 3. Results for coupled plasma-neutral transport modeling procedure for the limite: case

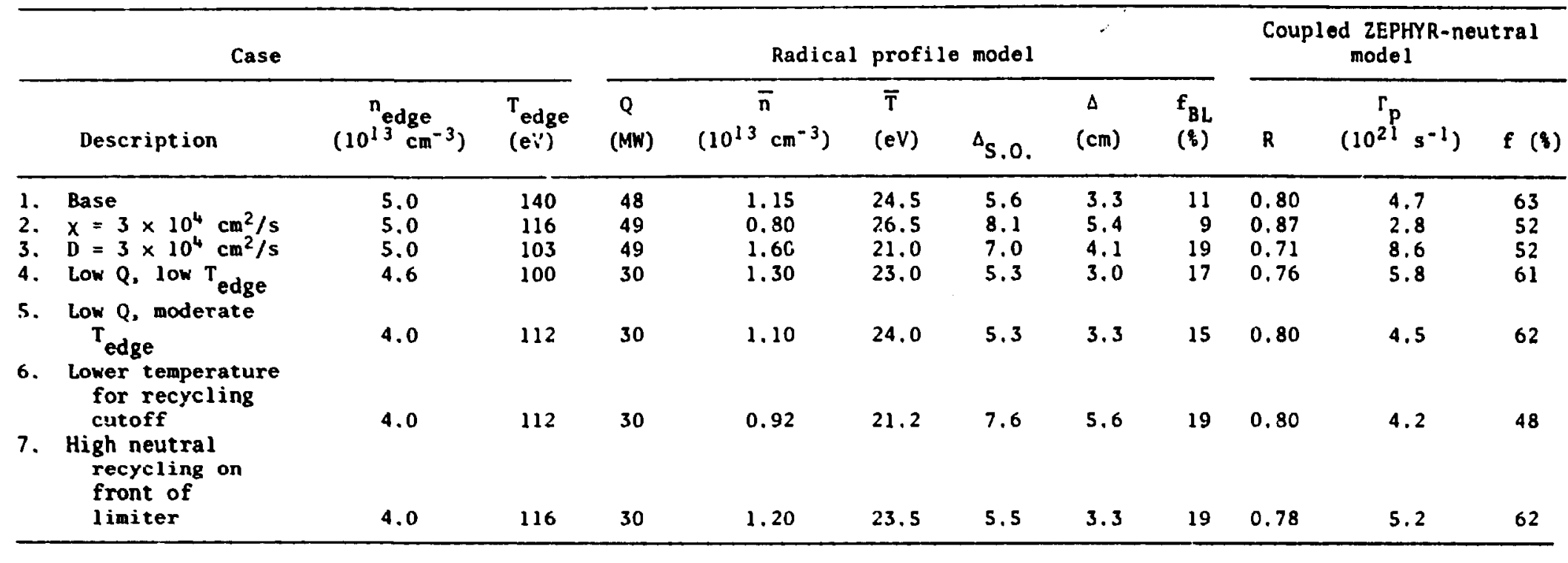


throat). For the pump-limiter case corsidered here, about one-half to two-thirds of this flow is pumped. The plasma flow under the limiter is

$$
r_{T} \sim \Delta \times \bar{n}_{t} \times v_{t},
$$

where $V_{t}$ is the plasma flow speed at the throat. For conditions typical of the plasma considered here, the plasma flow speed at the throat is most strongly affected by the neutral recycling that occurs near the neutralizer plate, $R$. Increases in $R$ tend to decrease the throat flow speed (see ref. 13). Variations of the pumping rates shown in Table 3 are explained by variations in the three parameters on the right-hand side of Eq. (17) as discussed in the following paragraphs.

Increasing $x$ (case 2 compared to case 1 ) results in a wider S.0., which tends to increase the neutral recycling. The increased recycling slows the plasma flow rate into the throat, which overwhelms the effects of a larger $\Delta$ in Eq. (17) and results in a net decrease of the neutral pumping. Increasing $D$ (case 3 compared to case 1) only slight ly changes $\Delta$, but in this case there are stronger gradients along the field line and a lower plate temperature $(<20 \mathrm{eV})$. This condition results in a slightly lower recycling than case 1 because of the reduced neutral ionization probability. The lower recycling in case 3 coupled with the higher average density at the throat results in the highest pumping rate of any of the cases shown in Table 3. Rather than specify the fraction of the S.O. that flows below the limiter, the location of the leading edge is determined here by the criterion that the heat flux has fallen to $200 \mathrm{~W} / \mathrm{cm}^{2}$. As seen in Table 3, the fraction of plasma flowing out at the S.0. that goes below the limiter $f_{B L}$ is $\approx 10-20 \%$. This fraction tends to increase as the neutral recycling below the limiter, $R$, decreases.

Cases 4-7 in Table 3 use edge densities and temperatures that result in integrated heat fluxes $Q$ of $30 \mathrm{MW}$. These cases generally have a smaller portion of the S.O. impinging on the front surface of the limiter, but the parameters for the part of the S.O. flowing behind the limiter are similar to those of Cases 1-3. The largest pumping rate 
found in cases 4-7 is for the low edge temperature example (case 4), which has the lowest recycling. The lower input for the edge temperature has the consequence of a lower average throat temperature (and even lower temperatures near the neutralizer plate) than the other cases, which is responsible for the small recycling value. The last two examples in Table 3 indicate little effect on the neutral pumping rates from changes in the assumptions about the recycling profile used in the radial profile model. Case 6 uses a lower temperature $(5 \mathrm{eV})$ for the neutral recycling cutoff in the radial profile model, and case 7 assumes that high neutral recycling also occurs on the front surface of the limiter. It is interesting to note that the pumping rate tends to increase with high recycling on the front surface of the limiter (case 7 compared to case 5). High neutral recycling on the front surface is desirable as a mechanism for reducing erosion rates. ${ }^{7}$ With high neutral recycling on the front surface of the limiter (case 7), the average density of the plasma beneath the limiter is slightly higher than that of case 5 , and the temperature is slightly lower (hence lower neutral recycling). These effects result in an increased plasma flow rate underneath the limiter, which produces a larger pumping rate.

In general, the cases in Table 3 with the lowest recycling have the highest neutral pumping rates. Also, it is seen that variations in the assumptions inherent co the model show factors of uncertainty in the neutral pumping rates on the order of 2 . The neutral pumping rate required for the exhaust in $\operatorname{TFCX}^{16}$ is $n 2 \times 10^{21} \mathrm{~s}^{-1}$. This rate corresponds to $250 \mathrm{MW}$ of fusion power and a $5 \%$ helium density ratio and assumes that helium transport (neutral and plasma) is equivalent to that of hydrogen. The neutral pumping rates shown in Table 3 indicate that adequate neutral particle removal rates for the exhaust requirements are possible for the pump-limiter configuration with $S_{\text {eff }}=2.2 \times 10^{5} \mathrm{~L} / \mathrm{s}$.

All results to this point have been calculated using the same pump speed. Figure 9 showns the variation of the neutral pumping rate with different pump speeds. These results are for the same input conditions as case 5 in Table 3 . The increase in neutral pumping rates with higher pumping speeds is primarily due to two effects: (1) lower neutral 


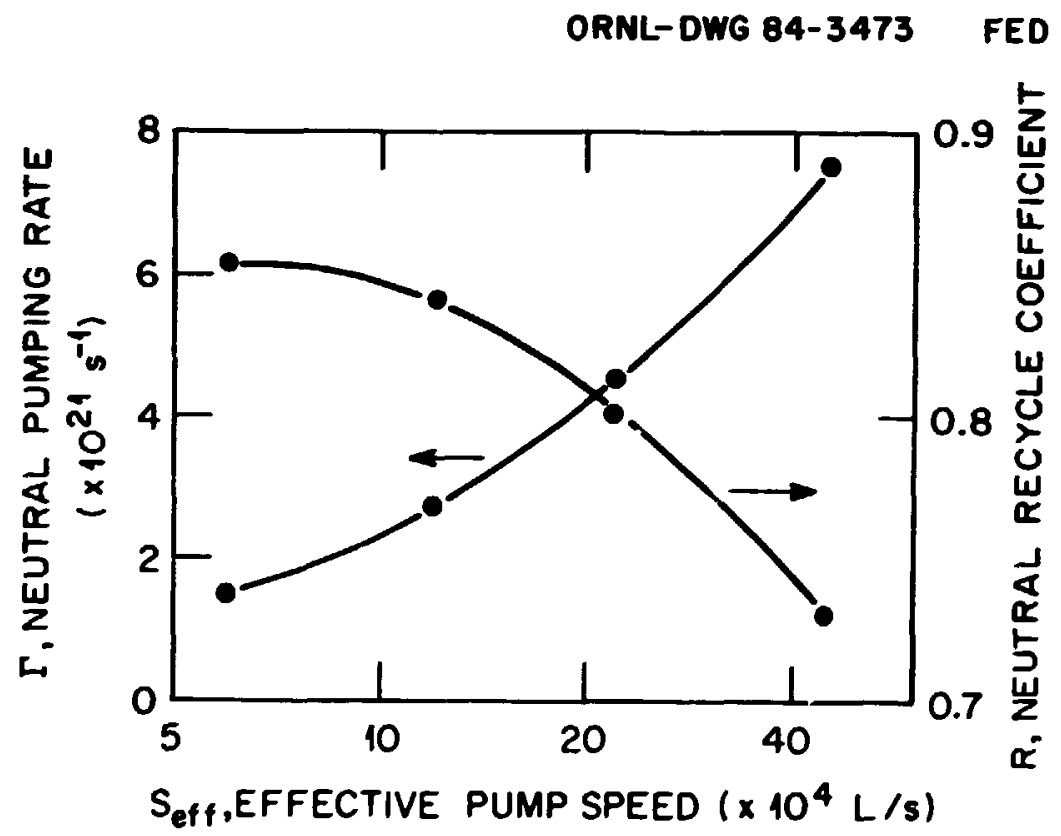

Fig. 9. Neutral pumping rate and neutral recycling vs effective pump speed for a limiter case. 
recycling and (2) a larger fraction of the plasma flowing into the throat being subsequently pumped as neutrals (pumping fraction) instead of escaping back toward the main plasma. The plasma flow into the throat for the $4.5 \times 10^{5}-\mathrm{L} / \mathrm{s}$ example is approximately twice that of $6 \times 10^{4}-\mathrm{L} / \mathrm{s}$ example, and this difference is related to the higher neutral recycling for the latter case. Also, the pumping fraction of the plasma flow into the throat is 2.5 tines higher for the $4.5 \times 10^{5} \mathrm{-L} / \mathrm{s}$ case compared to the $6 \times 10^{4}-\mathrm{L} / \mathrm{s}$ case. The combination of the two effects results in a pumping rate that is $\approx 5$ times higher for the $4.5 \times$ $10^{5}-\mathrm{L} / \mathrm{s}$ case.

Although the plasma flow rate into the throat for the case with $S_{\text {eff }}=4.5 \times 10^{5} \mathrm{~L} / \mathrm{s}$ is approximately twice that for the $6 \times 10^{4}-\mathrm{L} / \mathrm{s}$ case, the plasma flow rate onto the bottom of the limiter (i.e., the neutral production rate) is larger for the case with lower pump speed. The additional source of plasma flow onto the limiter for the $6 \times 10^{4} \mathrm{-L} / \mathrm{s}$ case arises from the larger neutral recycling. The fraction of the neutrals produced at the plate that are pumped is relatively small (i.e., $8 \%$ for $S_{\text {eff }}=6 \times 10^{4} \mathrm{~L} / \mathrm{s}$ and $21 \%$ for $S_{\text {eff }}=4.5 \times 10^{5} \mathrm{~L} / \mathrm{s}$ ), with the bulk of the neutrals produced at the plate being ionized for both cases.

\subsection{DIVERTORS}

For the divertor case, the entire radial extent of the S.0. is included in the neutral pumping calculations, as opposed to the limiter case in which only the outer portion was involved. Consequently, much larger temperature and density variations are involved in the divertor case. To take some account of the larger probability of neutral ionization in the higher density and higher temperature portion of the S.O., the recycling profile $R(r)$, which is used in the radial profile model, is chosen in the following manner. The recycling is decreased linearly from a peak value at $\mathbf{r}=0$ to a lower value at the point where $\mathrm{T}=20 \mathrm{eV}$. The peak (lower) value is taken so that the amount of recycling is doubled (halved) compared the reference value. The intermediate value is used for comparison with that predicted by the coupled ZEPIIYR-neutral model. Otherwise the modeling procedurc is the same as that 
described for the limiter cases. Figure 10 shows the density and temperature profiles found with the radial profile model and the associated neutral recycling profile for a divertor case using an edge temperature (density) of $165 \mathrm{eV}\left(4.5 \times 10^{13} \mathrm{~cm}^{-3}\right)$. The integrated heat flux $Q$ for this case is $30 \mathrm{MW}$. Also, $S_{\text {eff }}=2.1 \times 10^{5} \mathrm{~L} / \mathrm{s}$ and $X=D=10^{4} \mathrm{~L} / \mathrm{s}$ are used.

Figure 11 shows the profiles for density, temperature, and flow speed along the scrape-off field lines found with the ZEPHYR-neutral code using input fron the information displayed in Figure 10. A neutral pumping rate of $5.8 \times 10^{21} \mathrm{~s}^{-1}$ is found in this case, and the neutral recycling coefficient is 0.86 . The divertor channel geometry (Fig. 6) is more open for neutral penetration toward the main plasma than the limiter-channel geometry. As a result, a larger fraction of the neutral flux leaving the divertor channel exits as neutrals escaping toward the main plasma rather than as pumped neutrals. In this case, only about one-fifth of the neutrals leaving the divertor channel are pumped, compared to corresponding fractions of more than one-half for the pumplimiter cases in Table 3.

Variation of the neutral pumping rate vs $S_{\text {eff }}$ for the conditions used in the preceding case is shown in Fig. 12. The increase in neutral pumping rates with larger $S_{\text {eff }}$ is caused by the punping of a larger fraction ( $f$ ) of the plasma flow into the divertor channel. Unlike the pump-limiter cases, the recycling is insensitive to changes in $S_{\text {eff }}$ (see Fig. 12), and the total plasma flow rate into the divertor only changes slightly with $S_{\text {eff }}$. The lack of sensitivity of $R$ to changes in $S_{\text {eff }}$ is due to the small percentage of neutrals leaving the divertor channel as pumped neutrals. Also, it is evident that the neutral pumping rates for divertors are comparable to those of pump-limiters. Although the divertor case has more plasma flowing into the divertor channel than the limiter case, the smaller percentage of it that is punped tends to even out tho net pumping rate. To satisfy the exhaust requirement of a particle remo: $: 1$ rate $\gtrsim 2 \times 10^{21} \mathrm{~s}^{-1}$ from $F i g .12$, it is seen that $\mathrm{s}_{\text {eff }}$ must be $\gtrsim 10^{5} \mathrm{~J} / \mathrm{s}$. 


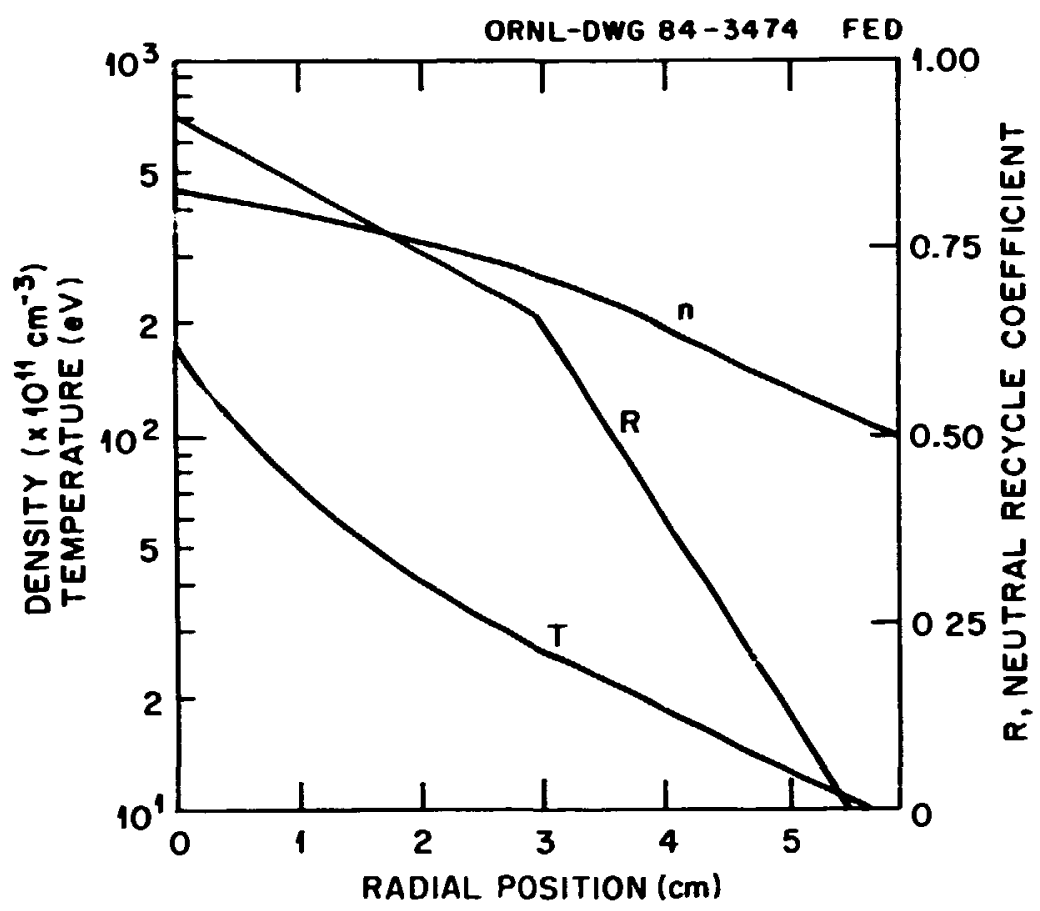

Fig. 10. Density $n$, temperature $T$, and neutral recycle coefficient $R$ vs radial distance from main plasma for a divertor case.

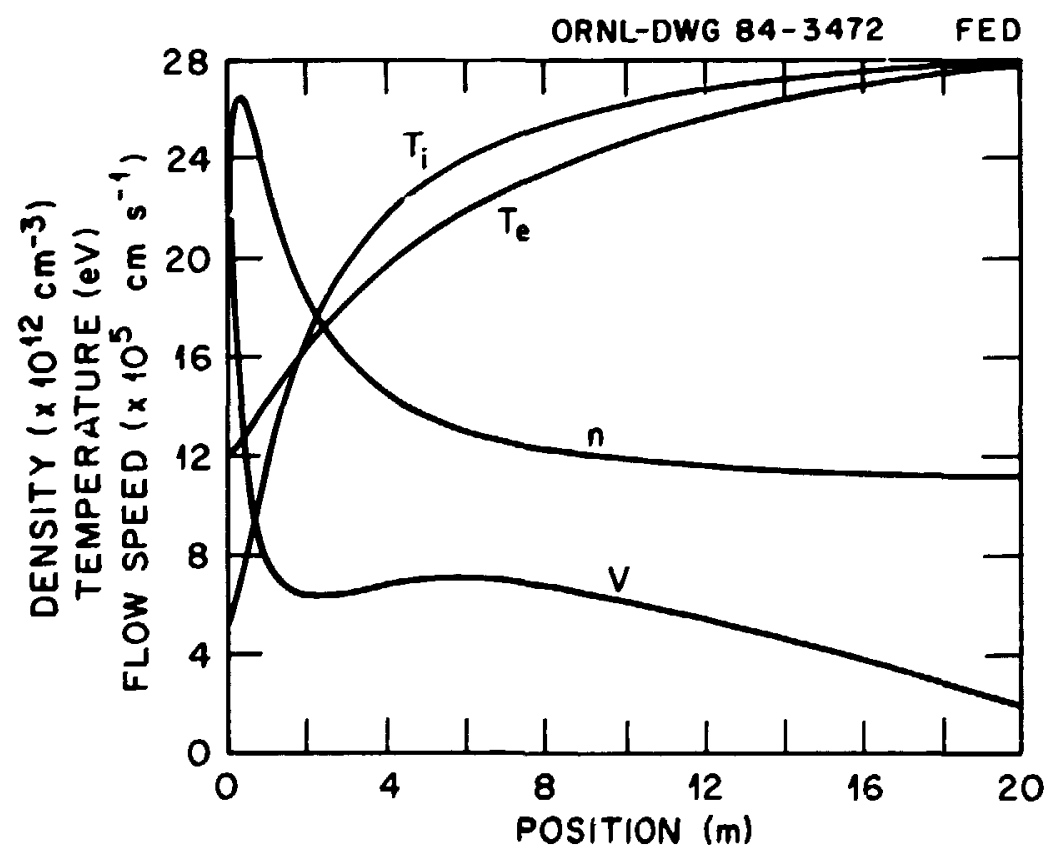

Fig. 11. Ion temperature $T_{i}$, electron temperature $T_{e}$, density $n$, and flow speed $V$ vs distance along the field line from the neutralizer plate for a divertor case. 


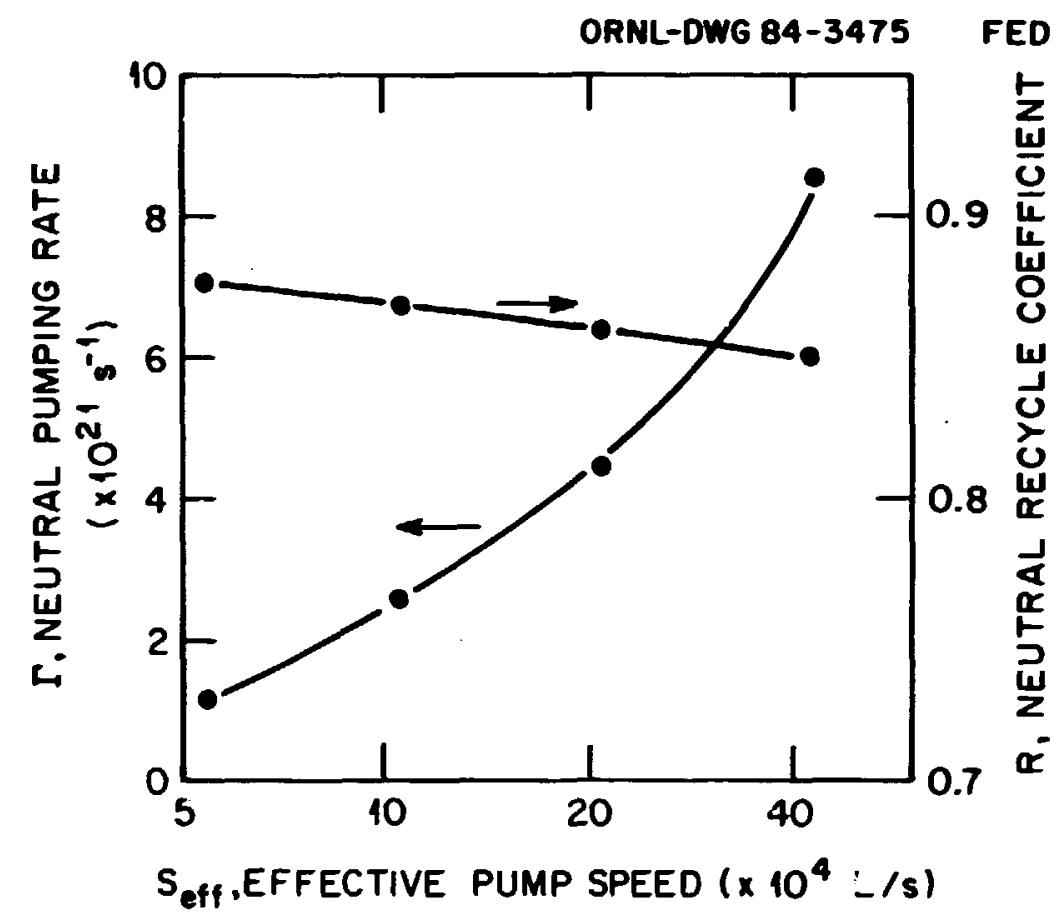

Fig. 12. Neutral pumping rate and neutral recycling vs effective pump speed for a divertor case. 


\section{CONCLUSIONS}

\subsection{SUMMARY}

Investigation of the scrape-off region requires modeling the plasma transport across field lines and including the associated effects of neutral recycling. The method used in this work involves the use of separate models for each of these aspects that are coupled through an iteration procedure that checks the assumptions of one component with the output from another. This approach is a first step for the study of the scrape-off region including two-dimensional (2-D) plasma transport effects and those of the coupled neutral transport and requires only minimal numerical effort. The method was applied here to the study of neutral pumping rates in the pump-limiter and divertor options for the proposed TFCX experiment. It was found that high neutral recycling in the vicinity of the neutralizer plate has important ramifications on the evaluation of pumping rates for both the pump-limiter and the divertor. In both cases, the plasma flow into the channel surrounding the neutralizer plate is greatly reduced by the neutral recycling. The fraction of this flow that is pumped can be large $(>50 \%)$, but in general it is dependent on the particular geometry and plasma conditions. It was found that pumping speeds $\geq 10^{5} \mathrm{~L} / \mathrm{s}$ are adequate for the exhaust requirements in the pump limiter and the divertor cases.

\subsection{LIMITATIONS OF MODEL AND FUTURE DIRECTIONS}

The primary limitation of the technique used here is the use of averaged results from one component of the iteration procedure as input for calculations of other components. For instance, the simple neutral transport model used here provides a single recycling coefficient based on calculations using averaged plasma parameters and a scrape-off width provided by the radial profile model. A possible next step, which would provide a more accurate treatment of the transport along the field lines at each radial location, would be to use a Monte Carlo neutral transport model to provide the recycling coefficient as a function of radial position. This information could then be coupled to a method similar to 
the radial profile model used here to permit a better treatment of the outer radial extent of the scrape-off plasma (with temperatures $\leq 20 \mathrm{eV}$ ), which could have a large contribution to the total plasma flow rate toward the reutralizer plate due to its transparency to neutral recycling. 


\section{REFERENCES}

1. H. C. Howe, Physics Considerations for the FED Limiter, ORNL/TM-7803, Oak Ridge Natl. Lab., 1981.

2. M. Ulrickson. Optimu Shapes for Pump Limiters, PPPL-1901, Princeton Plasma Physics Lab., Princeton, N.J., 1982.

3. M. U1rickson, Particle and Energy Transport in the Plasma Scrape-off Zone and its Impact on Limiter Design, PPPL-1987, Princeton Plas'na Physics Lab., Princeton, N.J., 1983

4. J. M. Ogden et al., IEEE Trans. Plasma Sci. PS-9, 274 (1981).

5. A. T. Mense and G. A. Emmert, Nucl. Fusion 19, 361 (1979).

6. M. Petravic, D. Heifetz, and D. Post, J. Mucl. Mater. 111 \& 112 , 294 (1982).

7. M. Petravic et al., Phys. Rev. Lett. 48, 326 (1982).

8. P. T. Harbour and J. G. Morgan, Model and Codes for the Plasma Edge Region, CLM-R-234, Culham Lab., Abingdon, England, 1982.

9. M. Shimada and JAERI Team, J. Nucl. Mater. 121, 126 (1984).

10. W. Schneider et al., J. Nucl. Mater. 121, 178 (1984).

11. M. F. A. Harrison, P. J. Harbour, and E. S. Hotson, NucZ. Technol./Fucion 3 , 432 (1982).

12. E. Cupini et al., Monte Carlo Studies of Heliwn Proming and Sputtering in the INTOR Divertor, Commission of the European Communities, Directorate General XII-Fusion Programne, Brussels, 1984.

13. J. Galambos and M. Peng, Two Point Model for Divertor Transport, ORNL/FEDC-83/14, Fusion Engineering Design Center, Oak Ridge Natl. Lab., 1984.

14. J. Ga lambos and M. Peng, J. Nucl. Mater. 121, 205 (1984).

15. D. Heifetz et al., J. Comput. Phys. 46, 309 (1982).

16. J. A. Schmidt et al., "The Toroidal Fusion Core Experiment Studies," paper IAEA-CN-44/H-I-3 presented at the 10th Inter.ational Conference on Plasma Physics and Controlled Nuclear Fusion Research, London, September 1984; to be published in the proceedings.

17. D. Heifetz et al., J. Nucl. Mater. 111 \& 1 12, 298 (1982).

18. R. L. Freeman and E. M. Jones, Atomic Collision Processes in Plasma Physics Experiments, CLM-R-137, Culham Lab., Abingdon, England, 1984. 
ORrvij/FEDC-84/6

Dist. Category UC-20 c,d

INTERNAL DISTRIBUTION

1. S. K. Borowski

2. E. C. Crume

3. J. L. Dunlap

4-8. J. D. Galambos

9. G. E. Gorker

10. Y-K. M. Peng

11. J. A. Rome

12. M. J. Saltmarsh

13. T. E. Shannon

14. J. Slieffielí

15. V. C. Srivastava
16. D. J. Strickler

17. N. A. Uckan

18. T. Uckan

19-20. Laboratory Records Department

21. Laboratory Records, ORNL-RC

22. Document Reference Section

23. Central Research I ibrary

24. Fusion Energy Division Library

25-26. Fusion Energy Division Publications Office

27. ORNL Patent Office

\section{EXTERNAL DISTRIBUTION}

28. M. A. Abdou, Boelter Hall, University of California, Los Angeles, CA $90<<4$

29. N. A. Amherd, Fusion Power Program, Advanced Systems Department, Electric Power Research Institute, P.O. Box 10412, Palo Alto, CA 94304

30. J. L. Anderson, CMB-3, Mail Stop 348, Los Alamos National Laboratory, P.O. Box 1663, Los Alamos, NM 87545

31. M. Anderson, Tennessee Valley Authority, 1300 Commerce Bank Building, Chattanooga, TN 37401

32. O. A. Anderson, Lawrence Berkeley Laboratory, University of California, Berkeley, CA 94720

33. D. J. Anthony, Advanced Power Program, Advanced Energy Programs Department, Building 2, Room 551, General Electric Company, Schenectady, NY 12345

34. C. C. Baker, FPP/208, Argonne National Laboratory, 9700 South Cass Avenue, Argonne, IL 60439

35. T. H. Batzer, L-536, Lawrence Livermore National Laboratory, P.0. Box 808, Livermore, CA 94550

36. J. E. Baublitz, Office of Fusion Energy, Office of Energy Research, Mail Station G-256, U.S. Department of Energy, Washington, DC 20545

37. W. Bauer, Physical Research Division, Sandia National Laboratories-Livermore, Livermore, CA 94550

38. J. F. Baur, GA Technologies, Inc., P.O. Box 81608, San Diego, CA 92138

39. D. S. Beard, Office of Fusion Energy, Office of Energy Research, Mail Station G-256, U.S. Department of Energy, Washington, DC 20545 
40. R. J. Beeley, ETEC, Rockwell International, P.O. Box 1449, Canoga Park, CA 91304

41. D. C. Berkey, vice Presider* \& General Manager, Energy System and Technology Division, General Electric Company, P.O. Box 7600, Stamford, CT 06904

42. K. L. Black, Department E452, McDonneii Douglas Astronautics Company, P.O. Box 516, St. Louis, MO 63166

43. R. Botwin, C47-05, Grı Iman Aerospace Corporation, P.O. Box 31, Bethpage, NY 11714

44. W. B. Briggs, McDonnell Dougias Astronautics Company, Y.O. Box 516, St. Louis, MO 63166

45. G. Bronner, Princeton Plasma Physics Laboratory, P.O. Box 451, Princeton, NJ 08544

46. J. N. Brooks, FPP/207, Argonne National Laboratory, 9700 South Cass Avenue, Argonne, IL 60439

47. S. C. Burnett, GA Technologies, Inc., P.O. Box 81608, San Diego, CA 92138

48. J. D. Callen, Department of Nuclear Engineering, University of Wisconsin, Madison, WI 53706

49. V. S. Chan, GA Technologies, Inc., P.O. Box 81608, San Diego, CA 92138

50. R. G. Clemmer, Fusion Power Program, Argonne National Laboratory, 9700 South Cass Avenue, Argonne, IL 60439

51. D. R. Cohn, MIT Plasma Fusion Center, 167 Albany Street, Cambridge, MA 02139

52. W. S. Cooper, Lawrence Berkeley Laboratory, University of California, Berkeley, CA 94720

53. J. W. Coursen, C36-05, Grumman Aerospace Corporation, P.O. Box 31, Bethpage, NY 11714

54. R. W. Conn, School of Chemical, Nuclear, and Thermal Engineering, Boelter Hall, University of California, Los ingeles, CA 90024

55. J. G. Crocker, EG\&G Idaho, P.O. Box 1625, Idaho Falls, ID 83401

56. A. E. Dabiri, Energy Systems and Conservation Division, Science Applications International Corporation, P.O. Box 2351, La Jolla, CA 92038

57. C. C. Damm, L-441, Lawrence Livermore National Laboratory, P.O. Box 808, Livermore, CA 94550

58. R. C. Davidson, Massachusetts Institute of Technology, 77 Massachusetts Avenue, Cambrídge, MA 02139

59. N. A. Davies, Office of Fusion Energy, Office of Energy Research, Mail Station G-256, U.S. Departinent of Energy, Washington, DC 20545

60. J. W. Davis, E457, Building 81/1/B7, McDonnell Douglas Astronautics Company, P.O. Box 516, St. Louis, MO 63166

61. M. J. Davis, Sandia National Laboratories, P.O. Box 5800, Albuquerque, NM 87185

62. S. O. Dean, Director, Fusion Energy Development, Science Applications, Inc., 2 Professional Drive, Suite 249, Gaithersburg, MD 20760

63. J. F. Decker, Office of Fusion Energy, Mail Station G-256, U.S. Department of Energy, Washington, DC 20545

64. D. DeFreece, E451, Building 81/1/B7, McDonnell Douglas Astronautics Company, P.O. Box 516, St. Louis, MO 63166

65. A. Deitz, Princeton Plasma Physics Laboratory, P.O. Box 451, Princeton, NJ 08544

66. D. A. Dingee, Program Manager, Fusion Technology, Pacific Northwest Laboratories, Battelle Boulevard, Richland, WA 99352

67. J. N. Dogg; it, L $-i 1$ 1, Lawrence Livermore National Laboratory, P.O. Box 808, Livermore, CA 94530 
68. H. Dreicer, Division Leader, CRT, Los Alamos National Laboratory, P.O. Box 1663, Los Alamos, NM 87545

69. D. Ehst, Argonne National Laboratory, 9700 South Cass Avenue, Argonne, IL 60439

70. W. R. Ellis, Office of Fusion Energy, Mail Station G-256, U.S. Department of Energy, Washington, DC 20545

71. B. A. Engholm, GA Technologies, Inc., P.O. Box 81608, San Diego, CA 92138

72. H. P. Eubank, Princeton Plasma Physics Laboratory, P.O. Box 451, Princeton, NJ 08544

73. F. Farfaletti-Casali, Engineering Division, Joint Research Center, Ispra Establishment, 21020 Ispra (Varese), Italy

74. J. J. Ferrante, Manager, Building 36-241, Large Superconducting Program, General Electric Company, I River Road, Schenectady, NY 12345

75. J. File, Princeton Plasma Physics Laboratory, P.O. Box 451, Princeton, NJ 08544

76. P. A. Finn, Fusion Power Program, Argonne National Laboratory, 9700 South Cass Avenue, Argonne, IL 60439

77. H. K. Forsen, Bechtel Group, Inc., Research \& Engineering, P.O. Box 3965, San Francisco, CA 94119

78. J. S. Foster, Jr., Building R4-2004, TRW Defense and Space Systems, 1 Space Park, Redondo Beach, CA 90278

79. T. K. Fowler, Associate Director for MFE, L-436, Lawrence Livermore National Laboratory, P.O. Box 808, Livermore, CA 94550

80. J. W. French, EBASCO Services, Inc., Forrestal Campus, CN-59, Princeton University, Princeton, NJ 08544

81. H. P. Furth, Director, Princeton Plasma Physics Laboratory, P.O. Box 451, Princeton, NJ 08544

82. J. G. Gavin, Jr., Presidert, A01-11, Grumman Aerospace Corporation, P.O. Box 31, Bethpage, NY 11714

83. G. Gibson, Westinghouse Electric Corporation, Fusion Power Systems Department, P.O. Box 10864, Pittsburgh, PA 15236

84. J. R. Gilleland, Manager, Fusion Project, GA Technologies, Inc., P.O. Box 81608, San Diego, CA 92138

85. M. Y. Gohar, Argonne National Laboratory, 9700 South Cass Avenue, Argonne, IL 60439

86. W. D. Goins, Tennessee Valley Authority, 1300 Commerce IJicn Bank Building, Chattanooga, TN 37401

87. D. A. Goldberg, Lawrence Berkeley Laboratory, University of California, Berkeley, CA 94720

88. R. Goldston, Princeton Plasma Physics Laboratory, P.O. Box 451, Princeton, NJ 08544

89. M. B. Gottlieb, Princeton Plasma Physics Laboratory, P.O. Box 451, Princeton, NJ 08544

90. R. W. Gould, Department of Applied Physics, California Institute of Technology, Pasadena, CA 91109

91. M. W. Griffin, Department E236, McDonnell Douglas Astronautics Company, P.O. Box 516, St. Louis, MO 63166

92. R. A. Gross, Plasma Research Laboratory, Columbia University, New York, NY 10027

93. C. R. Head, Office of Fusion Energy, Mail Station G-256, U.S. Department of Energy, Washington, DC 20545 
94. W. Heinz, Institut für Technische Physik, Kernforschungszentrum Karlsru'e GmbH, Postfach 3640, 7500 Karlsruhe 1, Federal Republic of Germany

95. C. D. Henning, Lawrence Livermore National Laboratory, P.O. Box 808, Livermore, CA 94550

96. G. K. Hess, Office of Fusion Energy, Mail Station ER-701, U.S. Department of Energy, Washington, DC 20545

97. T. Hiraoka, JT-60 Project Office I, Japan Atomic Energy Research Institute, Tokai Research Establishment, Tokai, Ibaraki, Japan

98. R. L. Hirsch, Manager, Synthetic Fuels Reszarch, Exxon Research and Engineering Company, P.O. Box 4255, Baytown, TX 77520

99. J. J. Holmes, Westinghouse-Hanford Engineering Development Laboratory, P.O. Box 1970, Richland, WA 99352

100. W. G. Homeyer, GA Technologies, Inc., P.O. Box 81608, San Diego, CA 92138

101. J. C. Hosea, Princet n Plasma Physics Laboratory, P.O. Box 451, Princetoil, NJ 08544

102. D. Hwang, Princeton Plasma Physics Laboratory, P.O. Box 451, Princeton, NJ 08544

103. G. J. Inukai, Department E231, McDonnell Douglas Astronautics Company, P.O. Box 516, St. Louis, MO 63166

104. D. L. Jassby, Princeton Plasma Physics Laboratory, P.O. Box 451, Princeton, NJ 08544

105. J. B. Joyce, Princeton Plasma Physics Laboratory, P.O. Box 451, Princeton, NJ 08544

106. R. A. Krakowsi, CTR-12, Mail Stop 641, Los Alamos National Laboratory, P.O. Box 1663, Los Alamos, NM 87545

107. W. Krueger, NW16-160, 167 Albany St., Cambridge, MA 02139

108. G. L. Kulcinski, University of Wisconsin, Department of Nuclear Er,ziniering, Engineering Research Building, Room 439, 1500 Johnson Drive, Madison, WI 53706

109. D. L. Kummer, McDonnell Douglas Astronautics Company, P.O. Box 516, St. Louis, MO 63166

110. T. S. Latham, Mail Stop 44, United Technologies Research Center, Silver Lane, East Hartford, CT 06108

111. L. R. Ledman, Office of Fusion Energy, Mail Station G-256, U.S. Department of Energy, Washington, DC 20545

112. L. M. Lidsky, MIT Plasma Fusion Center, 167 Albany Street, Cambridge, MA 02139

113. C. S. Liu, GA Technologies, Inc., P.O. Box 81608, San Diego, CA 92138

114. E. F. Lowell, General Manager, Energy Systems Programs Department, Building 2-455, General Electric Company, 1 River Road, Schenectady, NY 12345

115. T. Luzzi, Grumman Aerospace, M.S. A08-35, Bethpage, NY 11714

116. D. J. McFarlin, Mail Stop 44, United Technologies Research Center, Silver Lane, East Hartford, CT 06108

117. R. McGrath, Fusion Power Program, Argonne National Laboratory, 9700 South Cass Avenue, Argonne, IL 60439

118. V. A. Maroni, CEN/205, Argonne National Laboratory, 9700 South Cass Avenue, Argonne, IL 60439

119. W. Marton, Office of Fusion Energy, Office of Energy Research, Mail Station G-256, U.S. Department of Energy, Washington, DC 20545 
120. L. G. Masson, EG\&G Idaho, Idaho National Engineering Laboratory, P.O. Box 1625, Idaho Falls, ID 83401

121. D. G. McAlees, Exxon Nuclear Company, Inc., 2101 Horn Rapids Road, Richland, WA 99352

122. D. M. Meade, Princeton Plasma Physics Laboratory, P.O. Box 451, Princeton, NJ 08544

123. A. T. Mense, Building 107, Post B2, McDonnell Douglas Astronautics Company, P.O. Box 516, St. Louis, MO 63166

124. L. Michaels, Princeton Plasma Physics Laboratory, P.O. Box 451, Princeton, NJ 08544

125. D. Mikkelsen, Princeton Plasma Physics Laboratory, P.O. Box 451, Princeton, NJ 08544

126. R. L. Miller, GA Technologies, Inc., P.O. Box \$1608, San Diego, CA 92138

127. R. G. Mills, Princeton Plasma Physics Laboratory, P.O. Box 451, Princeton, NJ 08544

128. O. Mitarai, Energy Conversion, Kyushu University, Kasuga Fukuoka Pr., Japan

129. J. T. D. Mitchell, Culham Laboratory, Abingdon, Oxforushire OX14 3DB, United Kingdom

130. R. W. Moir, Lawrence Livermore Laboratory, P.O. Box 808, Livermore, CA 94550

131. D. B. Montgomery, MIT Plasma Fusion Center, 167 Albany Street, Cambridge, MA 02139

132. K. Moses, R-1/1078, TRW Defense and Space Systems, 1 Space Park, Redondo Beach, CA 90278

133. R. E. Muller, Aerojet Manufacturing Company, P.O. Box 4210, Fullerton, CA 92934

134. A. E. Munier, Grumman Aerospace Company, P.O. Box 31, Bethpage, NY 11714

135. M. R. Murphy, Office of Fusion Energy, Mail Station G-256, U.S. Department of Energy, Washington, DC 20545

136. R. E. Nygren, FPP/207, Argonne National Laboratory, 9700 South Cass Avenue, Argonne, IL 60439

137. T. Ohkawa, GA Techrologies, Inc., P.O. Box 81608, San Diego, CA 92138

138. M. Okabayashi, Princeton Plasma Physics Laboratory, P.O. Box 451, Princeton, NJ 08544

139. D. Overskei, GA Technologies, Inc., P.O. Box 81608, San Diego, CA 92138

140. R. R. Parker, Francis Bitter National Magnet Laboratory, 170 Albany Street, Cambridge, MA 02139

141. B. Pease, Culham Laboratory, Abingdon, Oxfordshire OX14 3DB, United Kingdom

142. M. Pelovitz, Princeton Plasma Physics Laboratory, P.O. Box 451, Princeton, NJ 08544

143. F. W. Perkins, Princeton Plasma Physics Laboratory, P.O. Box 451, Princeton, NJ 08544

144. M. Petravic, Princeton Plasma Physics Laboratory, P.O. Box 451, Princeton, NJ 08544

145. M. Porkolab, Massachusetts Instituti, of Technology, 77 Massachusetts Avenue, Cambridge, MA 02139

146. D. E. Post, Princeton Plasma Physics Laboratory, P.O. Box 451, Princeton, NJ 08544

147. R. E. Price, Office of Fusion Energy, Office of Energy Research, Mail Station G-256, U.S. Department of Energy, Washington, DC 20545 
148. D. H. Priester, Office of Fusion Energy, Office of Energy Research, Mail Station G-256, U.S. Department of Energy, Washington, DC 20545

149. A. K. Prinja, Chemical and Nuclear Engineering Department, Boelter Hall, University of California, Los Angeles, CA 90024

150. F. A. Puhn, GA Technologies, Inc., P.O. Box 81608, San Diego, CA 92138

151. J. Purcell, GA Technologies, Inc., P.O. Box 81608, San Diego, CA 92138

152. R. V. Pyle, University of California, Lawrence Berkeley Laboratory, Berkeley, CA 94720

153. J. M. Rawls, GA Technologies, Inc., P.O. Box 81608, San Diego, CA 92138

154. P. J. Reardon, Princeton Plasma Physics Laboratory, P.O. Box 451, Princeton, NJ 08544

155. W. T. Reierson, Princeton Plasma Physics Laboratory, P.O. Box 451, Princeton, NJ 08544

156. M. Roberts, Office of Fusion Energy, Mail Station G-256, U.S. Department of Energy, Washington, DC 20545

157. J. D. Rogers, Los Alamos National Laboratory, P.O. Box 1663, Los Alamos, NM 87545

158. F. L. Robinson, Tennessee Valley Authority, 1300 Commerce Bank Building, Chattanooga, TN 37401

159. M. L. Rogers, Monsanto Research Corporation, Mound Laboratory Facility, P.O. Box 32, Miamisburg, OH 45342

160. M. N. Rosenbluth, RLM 11.218, Institute for Fusion Studies, University of Texas, Austin, TX 78712

161. L. Ruby, Lawrence Berkeley Laboratory, University of California, Berkeley, CA 94720

162. P. H. Rutherford, Princeton Plasma Physics Laboratory, P.O. Box 451, Princeton, NJ 08544

163. M. M. Sabado, EBASCO Services, Inc., A Site, Building 1-A, Forrestal Carnpus, Princeton, NJ 08544

164. J. A. Schmidt, Princeton Plasma Physics Laboratory. P.O. Box 451, Princeton, NJ 08544

165. J. Schultz, MIT Plasma Fusion Center, 167 Albany Street, Cambridge, MA 02139

166. F. R. Scott, Electric Power Research Institute, P.O. Box 10412, Palo Alto, CA 94304

167. G. Sheffield, Princeton Plasma Physics Laboratory, P.O. Box 451, Princeton, NJ 08544

168. C. E. Singer, Princeton Plasma Physic Laboratory, P.O. Box 451, Princeton, NJ 08544

169. T. J. M. Sluyters, Accelerator Department, Brookhaven National Laboratory, Upton, NY 11973

170. D. Smith, Materials Science Division, Argonne National Laboratory, 9700 South Cass Avenue, Argonne, IL 60439

171. G. E. Smith, Grumman Aerospace Corporation, P.O. Box 31, Bethpage, NY 11714

172. R. I. Smith, Board Chairman, Public Service Electric and Gas Company, 80 Park Place, Newark, NJ 07101

173. L. Soroka, Lawrence Berkeley Laboratory, University of California, Berkeley, CA 94720

174. L. Southworth, GA Technologies, Inc., P.O. Box 81608, San Diego, CA 92138 
175. W. M. Stacey, Jr., Georgia Institute of Technology, School of Mechanical Engineering, Atlanta, GA 30332

176. D. Steiner, Rensselaer Polytechnic Institute, Nuclear Engineering Department, NES Building, Tibbets Avenue, Troy, NY 12181

177. E. Stern, Grumman Aerospace Corporation, CN-59, Forrestal Campus, Princeton, NJ 08544

178. L. D. Stewart, Princeton Plasma Physics Laboratory, P.O. Box 451, Princeton, N. 08544

179. W. Stodiek, Princeton Plasma Physics Laboratory, P.O. Box 451, Princeton, NJ 08544

180. P. M. Stone, Office of Fusion Energy, Office of Energy Research, Mail Station G-256, U.S. Department of Energy, Washington, DC 20545

181. I. N. Sviatoslavsky, Room 33, Engineering Research Building, 1500 Johnson Drive, University of Wisconsin, Madison, WI 53706

182. T. Tamano, GA Technologies, Inc., P.O. Box 81608, San Diego, CA 92138

183. R. E. Tatro, Manager, Energy Systems, M.Z. 16-1070, General Dynamics-Convair Division, P.O. Box 80847, San Diego, CA 92138

184. F Tenney, Princeton Plasma Physics Laboratory, P.O. Box 451, Princeton, NJ 08544

185. F. Thomas, B-20-5, Grumman Aerospace Corporation, Bethpage, NY 11714

186. K. I. Thomassen, Lawrence Livermore National Laboratory, P.O. Box 808, Livermore, CA 94550

187. R. J. Thome, Francis Bitter National Magnet Laboratory, 170 Albany Street, Cambridge, MA 02139

188. S. L. Thomson, Bechtel Group, Inc., P.O. Box 3965, San Francisco, CA 94119

189. C. Trachsel, McDonnell Dcuglas Astronautics Company, P.O. Box 516, St. Louis, MO 63166

190. J. R. Treglio, General Dynamics-Convair Division, P.O. Box 80847, San Diego, CA 92138

191. A. W. Trivelpiece, Office of Fusion Energy, Office of Energy Research, Mail Station G-256, U.S. Department of Energy, Washington, DC 20545

192. L. R. Turner, Fusion Power Program, Argonne National Laboratory, 9700 South Cass Avenue, Argonne, IL 60439

193. M. A. Ulrickson, Princeton Plasma Physics Laboratory, P.O. Box 451, Princeton, NJ 08544

194. E. H. Valeo, Princeton Plasma Physics Laboratory, P.O. Box 45I, Princeton, NJ 08544

195. T. C. Varljen, Westinghouse Electric Corporation, P.O. Box 10864, Pittsburgh, PA 15236

196. R. Varma, Physical Research Laboratory, Navrangpura, Ahmedabad, India

197. H. F. Vogel, Los Alamos National Laboratory, P.O. Box 1663, Los Alamos, NM 87545

198. A. Wait, Building 36-421, General Electric Company, 1 River Road, Schenectady, NY 12345

199. K. E. Wakefield, Princeton Plasma Physics Laboratory, P.O. Box 451, Princeton, NJ 08544

200. D. Weldon, Los Alamos National Laboratory, P.O. Box 1663, Los Alamos, NM 87545

201. J. C. Wesley, GA Technologies Inc., P.O. Box 81608, San Diego, CA 92138 
202. S. Whitley, Tennessee Valley Authority, 1300 Commerce Bank Building. Chattanooga, TN 37401

203. W. R. Wilkes, Monsanto Research Corporation, Mound Laboratory Facility, P.O. Box 32, Miamisburg, OH 45342

204. J. E. Wilkins, EG\&G Idaho, Idaho National Engincering Laboratory, P.O. Box 1625, Idaho Falls, ID 83401

205. H. Willenberg, Mathematical Sciences Northwest, Inc., P.O. Box 1887, Bellevue, WA 98009

206. J. E. C. Williams, Francis Bitter National Magnet Laboratory, 170 Albany Street, Cambridge, MA 02139

207. P. Willis, Building 23, Room 298, General Electric Company, 1 River Road, Schenectady, NY 12345

208. T. F. Yang, MIT Plasma Fusion Center, 167 Alba:ly Street, Cambridge, MA 02139

209. H. HI. Yoshikawa, W/A-62, Hanford Engineering Development Laboratory, P.O. Box 1970, Richland, WA 99352

210. K. M. Young, Princeton Plasma Physics Laboratory, P.O. Box 451, Princeton, NJ 08544

211. N. E. Young, EBASCO Services, Inc., Princeton Plasma Physics Laboratory, P.O. Box 451, Princeton, NJ 08544

212. K. M. Zwilsky, National Materials Advisory Board, National Academy of Sciences, 2101 Constitution Avenue NW, Washington, DC 20418

213. Bibliothek, Max-Planck Institut fur Plasmaphysik, D-8046 Garching bei Munchen, Federal Republic of Germany

214. Bibliothek, Institut fur Plasmaphysik, KFA, Postfach 1913, D-5170 Julich, Federal Republic of Germany

215. Bibliotheque, Centre de Recherches en Physique des Plasmas, 21 Avenue des Bains, 1007 Lausanne, Switerland

216. Bibliotheque, Service du Confinement des Plasmas, CEA, B.P. No. 6, 92 Fontenayaux-Roses (Seine), France

217. Documentation S.I.G.N., Department de la Physique du Plasma et de la Fusion Controlee, Association EURATOM-CEA, Centre d'Etudes Nucleaires, B.P. 85, Centre du Tri, 38041 Grenoble, Cedex, France

218. Library, Culham Laboratory, UKAEA, Abingdon, Oxfordshire, OX14 3DB, England

219. Library, FOM-Instituut voor Plasma-Fysica, Rijnhuizen, Edisonbaan 14, 3439 MN Nieuwegein, Netherlands

220. Library, Institute of Physics, Academia Sinica, Beijing, Peoples Republic of China

221. Library, Institute for Plasma Physics, Nagoya University, Nagoya 464, Japan

222. Library, International Centre for Theoretical Physics, Triesie, Italy

223. Library, JET Joint Undertaking, Abingdon, Oxfordshire, OX14 3DB, England

224. Library, Laboratorio Gas Ionizzati, CP 56, 00044 Frascati, Rome, Italy

225. Plasma Research Laboratory, Australian National Laboratory, P.O. Box 4, Canberra, ACT 2000, Australia

226. Thermonuclear Library, Japan Atomic Energy Research Institute, Tokai, Naka, Ibaraki, Japan

227. Library, Plasma Physics Labnratory, Kyoto University, Gokasho, Uji, Kyoto, Japan 
228. Office of the Assistant Manager for Energy Research and Development, Department of Energy, Oak RidE= Operations, Oak Ridge, TN 37830

229-418. Given distribution as shown in $T$ )-4500. Magnetic Fusion Energy (Distribution Category UC-20 c,d: Reacır Materials and Fusion Systems) 


\section{ABSTRACT}

Allalysis of the scrape-off region requires treatment of the plasma transport along and across the field lines and inclusion of the neutral transport effects. A method for modeling the scrape-off region that is presented here uses separate models for each of these aspects that are coupled together through an iteration procedure that requires only minimal numerical effort. The method is applied here to estimate the neutral pumping rates in the pump-limiter and divertor options for a proposed deuteriumtritium (D-T) ignition experiment. High neutral recycling in the vicinity of the neutralizer plate dramatically affects pumping rates for both the pump-limiter and divertor. In both cases, the plasma flow into the channel surrounding the neutralizer plate is freatly reduced by the neutral recycling. The fraction of this flow that is pumped can be large $(>50 \%)$, but in general it is dependent on the particular geometry and plasma conditions. It is estimated that pumping speeds $\gtrsim 10^{5} \mathrm{~L} / \mathrm{s}$ are adequate for the exhaust requirements in the pump-limiter and the divertor cases. Also, high neutral recycling on the front surface of the limiter tends to increase the neutral pumping rate. 